\title{
Methods to Improve Routine Bioassay Monitoring for Freshly Separated, Poorly Transported Plutonium
}

D. E. Bihl

T. P. Lynch

E. H. Carbaugh

M. J. Sula

September 1988

Prepared for the U.S. Department of Energy under Contract DE-AC06-76RLO 1830

Pacific Northwest Laboratory Operated for the U.S. Department of Energy by Battelle Memorial Institute 


\title{
DISCLAIMER
}

This report was prepared as an account of work sponsored by an agency of the United States Government. Neither the United States Government nor any agency thereof, nor Battelle Memorial Institute, nor any or their employees, makes any warranty, expressed or implied, or assumes any legal liability or responsibility for the accuracy, completeness, or usefulness of any information, apparatus, product, or process disclosed, or represents that its use would not iniringe privately owned rights. Reference herein to any specific commercial product, process, or service by trade name, trademark, manufacturer, or otherwise does not necessarily constitute or imply its endorsement, recommendation, or favoring by the United States Government or any agency thereof, or Battelle Memorial Institute. The views and opinions of authors expressed herein do not necessarily state or reflect those of the United States Government or any agency thereof.

\author{
PACIFIC NORTHWEST LABORATORY \\ operated by \\ BATTELLE MEMORIAL INSTITUTE \\ for the \\ UNITED STATES DEPARTMENT OF ENERGY \\ under Contract DE-AC06-76RLO 1830
}

\begin{tabular}{|c|c|}
\hline \multicolumn{2}{|c|}{ Printed in the United State's of America } \\
\hline \multicolumn{2}{|c|}{ Available from } \\
\hline \multicolumn{2}{|c|}{ National Jechnical Information Service } \\
\hline \multicolumn{2}{|c|}{ United States Department of Commerce } \\
\hline \multicolumn{2}{|c|}{5285 Port Royal Road } \\
\hline \multicolumn{2}{|c|}{ Springheld, Virginia 22161} \\
\hline \multicolumn{2}{|c|}{ Nitis Price Codes } \\
\hline \multicolumn{2}{|c|}{ Microfiche $A B 1$} \\
\hline \multicolumn{2}{|c|}{ Printed Copy } \\
\hline & Price \\
\hline Pages & Codes \\
\hline Do1-025 & $\mathrm{A} 02$ \\
\hline $026-050$ & A03 \\
\hline $0,51-075$ & A04 \\
\hline $076 \cdot 100$ & $\mathrm{~A} 05$ \\
\hline $101-125$ & $A 06$ \\
\hline $126-150$ & $A 07$ \\
\hline $151-175$ & $A 0 B$ \\
\hline$T 76-200$ & $\mathrm{~A} 09$ \\
\hline $201-225$ & A 10 \\
\hline $226-250$ & A11 \\
\hline 251.275 & A12 \\
\hline $276-300$ & $A 13$ \\
\hline
\end{tabular}


PNL -6695

UC-41

METHODS TO IMPROVE ROUTINE BIOASSAY

MONITORING FOR FRESHLY SEPARATED,

POORLY TRANSPORTED PLUTONIUM

D. E. Bihl

T. P. Lynch

E. H. Carbaugh

M. J. Sula

September 1988

Prepared for the

U.S. Department of Energy

under Contract DE-ACO6-76RLO 1830

Pacific Northwest Laboratory

Richland, Washington 99352 
.

. 


\section{SUMMARY}

Several human cases involving inhalation of plutonium oxide at Hanford have shown clearance half-times from the lung that are much longer than the 500-day half-time recommended for class $Y$ plutonium in Publication 30 of the International Commission on Radiological Protection (ICRP). The more tenaciously retained material is referred to as super class $Y$ plutonium. The ability to detect super class $Y$ plutonium by current routine bioassay measurements is shown to be poor.

Pacific Northwest Laboratory staff involved in the Hanford Internal Dosimetry Program investigated four methods to see if improvements in routine monitoring of workers for fresh super class Y plutonium are feasible. The methods were lung counting, urine sampling, fecal sampling, and use of diethylenetriaminepentaacetate (DTPA) to enhance urinary excretion. Use of DTPA was determined to be not feasible. Routine fecal sampling was found to be feasible but not recommended. Recommendations were made to improve the detection level for routine annual urinalysis and routine annual lung counting. 


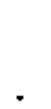




\section{ACKNOWLEDGMENTS}

The authors wish to express their appreciation to Keith Eckerman for providing the excretion curves for class $Y$ and super class $Y$ plutonium using the Leggett-Eckerman model, to Earl Palmer and Kit Kittinger for excellent reviews of drafts, to Susan Ennor for technical editing and for putting it all together, and to Marianna Cross for word processing. 



\section{CONTENTS}

SUMMARY .............................. $\mathrm{i} i \mathrm{i}$

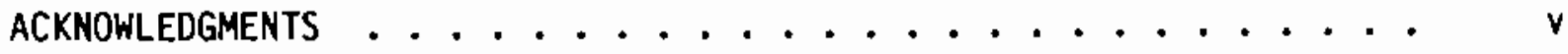

ACRONYMS AND ABBREVIATIONS ...................... xi

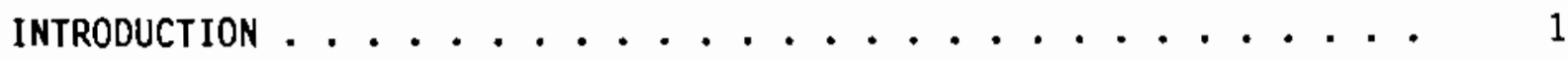

DETECTABILITY OF BIOASSAY MONITORING AT HANFORD FOR

CLASS Y AND SUPER CLASS Y PLUTONIUM .................. 3

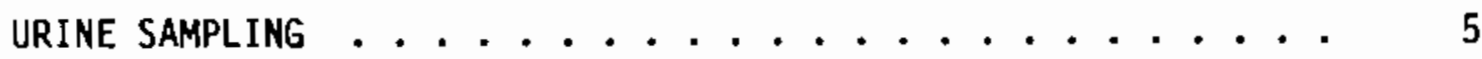

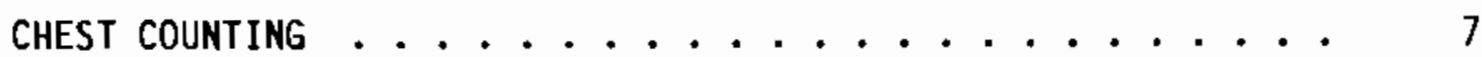

NEED FOR IMPROVED ROUTINE MONITORING . . . . . . . . . . . . 13

INVESTIGATION OF METHODS TO IMPROVE INTAKE MONITORING $\ldots \ldots$

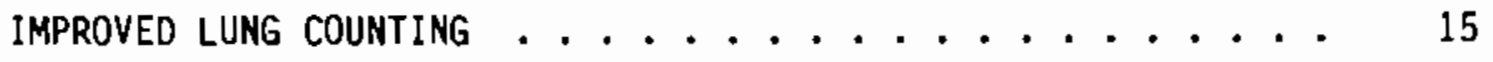

IMPROVEMENTS IN URINE SAMPLING OR URINALYSIS ....... 18

Frequency of Sampling ............ 18

Combining Samples ................. 19

Analytical Techniques ............. 19

Research ................ 25

ROUTINE FECAL SAMPLING .................... 25

Comparison of Two Fecal-Excretion Models ....... 25

Disadvantages ..................... 27

DRUG-ENHANCEMENT OF URINARY EXCRETION AS A ROUTINE

BIOASSAY METHOD ........................ 28

CONCLUSIONS AND RECOMMENDATIONS .................... 31

LUNG COUNTING .......................... 31

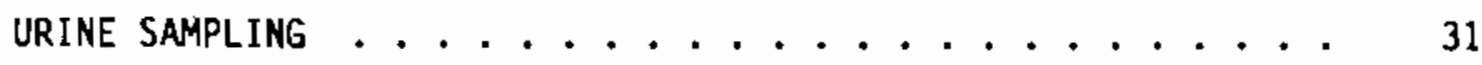




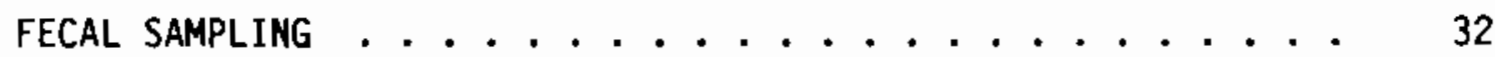

USE OF A DRUG TO ENHANCE URINARY EXCRETION . . . . . . . . 32

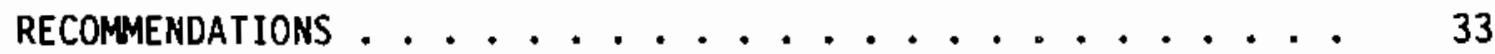

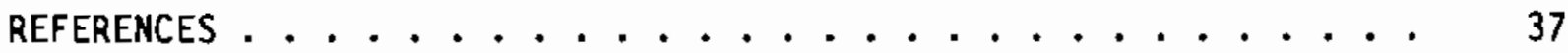

APPENDIX A - A CASE FOR SUPER CLASS Y PLUTONIUM . . . . . . . . . A.1

APPENDIX B - STUDIES OF FECAL EXCRETION BY BEAGLE DOGS . . . . . . B.1 


\section{FIGURES}

1 Urinary Excretion from Acute Inhalation of Class $Y$

Plutonium .........................

2 Urinary Excretion from Acute Inhalation of Super

Class Y Plutonium .....................

3 Ratio of 241 Am-to-23\%Pu Activity as a Function of Time

Post Separation for 6 and 12 wt\% $240 \mathrm{Pu}$ Mixtures.......

4 Americium-241 Lung Burden from an Acute Target

Detectable Intake....................

5 Minimum Detectable Intake of Super Class Y Plutonium

in Terms of Resulting First-Year Effective Dose Equivalent . .

6 Revised Minimum Detectable Intakes of Super Class $Y$ Plutonium in Terms of Resulting First-Year Effective Dose Equivalents ...................

7 Urinary Excretion from an Acute Target Detectable Inhalation of A) Class $Y$ Plutonium and B) Super Class $Y$ Plutonium Compared to Brookhaven National Laboratory's

MDA Adjusted for $240 \mathrm{Pu}$ Activity .............. 20

8 Comparison of Fecal-Excretion Models for Plutonium 0xide . . 27

A.1 ICRP 30 Lung Model for Class Y Material . . . . . . . . A.1 


\section{$\underline{\text { TABLES }}$}

1 Typical Bioassay Measurement Detection Levels for Plutonium and Americium ............ 3

2 Target Detectable Intakes for Fresh 6\% Plutonium Mixtures . . . 4

3 Doses from Minimum Detectable Intakes Using Routine Bioassay Measurements ............... . 10

4 Doses from Minimum Detectable Intakes Using Improved Lung-Counting Techniques . . . . . . . . . 17

5 Comparison of Plutonium in Urine As Analyzed by the Analytical Services Laboratory and Brookhaven National Laboratory ................. . . . 22

6 Summary of findings . . . . . . . . . . . . . . 34

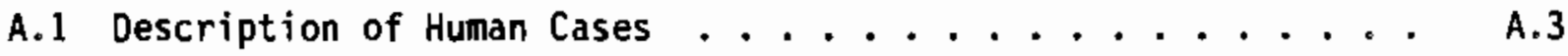




\section{ACRONYMS AND ABBREVIATIONS}

$\begin{array}{ll}\text { AMAD } & \text { activity median aerodynamic diameter } \\ \text { Brookhaven } & \text { Brookhaven National Laboratory } \\ \text { DOE } & \text { U.S. Department of Energy } \\ \text { DTPA } & \text { diethylenetriaminepentaacetate } \\ \text { FAP } & \text { fused aluminosilicate particles } \\ \text { FDA } & \text { U.S. Food and Drug Administration } \\ \text { FY } & \text { fiscal year } \\ \text { GI } & \text { gastrointestinal } \\ \text { HEHF } & \text { Hanford Environmental Health Foundation } \\ \text { ICRP } & \text { International Conmission on Radiological Protection } \\ \text { IND } & \text { investigational new drug } \\ \text { IV } & \text { intravenous } \\ \text { LANL } & \text { Los Alamos National Laboratory } \\ \text { MDA } & \text { minimum detectable activity } \\ \text { PNL } & \text { Pacific Northwest Laboratory } \\ \text { RPS } & \text { radiation protection standard } \\ \text { TD } & \text { target detectable }\end{array}$




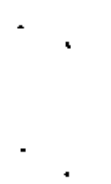




\section{INTRODUCTION}

In recent years the Hanford Internal Dosimetry Program(a) has become increasingly aware of evidence of a class of plutonium that, when inhaled, behaves quite a bit differently than would be predicted using the inhalation classes and the lung model defined in Publication 30 of the International Commission on Radiological Protection (ICRP 1979). The plutonium is much more tenaciously retained in the lung than normal class $Y$ material; consequently, this report refers to it as "super" class $Y$ plutonium. The evidence suggests that the chemical form of the plutonium is plutonium oxide. The characteristic that sets super class $Y$ plutonium material apart from nomal class $Y$ material is an extremely slow clearance rate from the lung. A more detailed discussion of super class $Y$ material and the evidence for it is presented in Appendix A.

Having assumed the existence of this super class $Y$ plutonium, program staff determined that it was necessary to review the capability of the routine bioassay-monitoring program to detect an acute inhalation exposure to the material. It is noted that routine bioassay monitoring is used as a means for documenting, on an individual-specific basis, that worker doses are less than some level. Routine bioassay monitoring is not a substitute for a prospective internal exposure monitoring program in the workplace.

This study evaluated 1) the detectability of an acute intake of class $Y$ and super class $Y$ plutonium through the present routine bioassay program and 2) methods to improve routine bioassay monitoring. The study did not evaluate either the capability of workplace monitoring or the detectability of chronic intakes or prolonged acute intakes (e.g., one to two weeks duration).

The ensuing sections discuss the ability of bioassay monitoring at Hanford to detect class $Y$ and super class $Y$ plutonium and the need for improved routine monitoring. The investigation of improved lung counting,

(a) The Hanford Internal Dosimetry Program is operated by Pacific Northwest Laboratory, which is operated by Battelle Memorial Institute for the U.S. Department of Energy under Contract DE-ACO6-76RLO 1830. 
urine sampling, fecal sampling, and enhancement (using diethylenetriaminepentaacetate [DTPA]) of urinary excretion as a routine bioassay method as ways to improve bioassay monitoring are also discussed. Conclusions and recommendations, based on the findings, are presented. 


\section{DETECTABILITY OF BIOASSAY MONITORING AT HANFORD FOR CLASS Y}

\section{AND SUPER CLASS Y PLUTONIUM}

Presently, routine bioassay monitoring of plutonium workers at Hanford consists of annual urinalysis and annual chest counts (1000 seconds) for plutonium. (a) Routine detection capabilities for these measurements are shown in Table 1. (The listed detection capabilities are based on a $5 \%$ probability each for Type I and Type II errors. Frequently, but not always, the substance of interest is detected at levels lower than the listed values.) Generally the nuclide of interest for chest counting is $241 \mathrm{Am}$ because it can be detected at a much lower level than jotopes of plutonium. Americium-241, in essence, is used as a tracer for plutonium.

Detectability is most useful when expressed in terms of the amount of an intake or the dose resulting from an intake. The conversion from detectability of a measurement to intake or dose depends on models. The ICRP 30 lung model and the ICRP 48 (ICRP 1986) systemic organ retention model were used to determine organ burdens and organ and effective dose equivalents. The Jones excretion model (Jones 1985) was applied to plutonium that reaches

TABLE 1. Typical Bioassay Measurement Detection Levels for Plutonium and Americium

\begin{tabular}{|c|c|c|c|}
\hline \multirow[b]{2}{*}{ Measurement } & \multicolumn{3}{|c|}{ Minimum Detectable Activity } \\
\hline & $238 \mathrm{pu}$ & $239 \mathrm{Pu}$ & $241_{\text {An }}$ \\
\hline $\begin{array}{l}\text { Chest counts, nci a }) \\
(1000 \mathrm{~s})\end{array}$ & 40 & 110 & 0.26 \\
\hline Urine, dpm/s ample & 0.02 & 0.02 & 0.02 \\
\hline
\end{tabular}

(a) Based on a 3-cm chest-wall thickness. Values will be 0.7 times lower when $2000-s$ counts become routine.

(a) It is anticipated that the time for routine chest counts will be increased to 2000 seconds by the start of calendar year 1989 . 
the blood to determine the urinary excretion as a function of time. For purposes of modelling, super class $Y$ plutonium is assumed to behave like normal class $Y$ plutonium except that, referring to Figure $A .1$ in Appendix $A$, the clearance half-times for compartments $a, c, e$, and $i$ were assumed to be 10,000 days. This decision was based in part on the data presented in Appendix $A$ and in part on the current thinking of the ICRP Task Group on Lung Models. (a)

Detectability was approached as follows. First, a provisional target level for detectability was established to be an intake or series of related intakes that result in an annual effective dose equivalent of $100 \mathrm{mrem}$; henceforth referred to as the target detectable (TD) intake. The TD intake was based on expected guidance from the U.S. Department of Energy (DOE) on internal exposure assessment. Next, the study answered two questions: "Can the TD intake be detected by present routine bioassay measurements?" and, if not, "What is the minimum intake that can be detected?"

The makeup of a TD intake, in terms of activities of isotopes in a plutonium/americium mixture, depends on the relative activities of those isotopes and the inhalation class. Table 2 gives the intake activities for class $Y$ and super class $Y$ plutonium for a mixture referred to as fresh, $6 \%$ plutonium. "Fresh" indicates that the plutonium has been processed to remove americium within two weeks prior to the hypothetical intake. "Six percent" refers to the amount by weight of 240 pu relative to the other isotopes of plutonium. Most plutonium mixtures encountered in the Hanford production facilities range from 6 to $12 \% 240 \mathrm{Pu}$, and the detectability is virtually the same for mixtures in that range. The assumption of fresh plutonium was used as a worst case because "old" plutonium is easier to detect by chest counting because of the $241_{\text {Am }}$ ingrown from $241 \mathrm{Pu}$. Therefore, this study deals only with fresh, 6\% plutonium.

(a) James, A. C., and A. Birchall. "Progress in Lung Modeling by the ICRP Task Group." In Proceedings of the Workshop on Biological Assessment on Occupational Exposure to Actinides, May 30-June 2, 1988, Versailles, France. To be published in Radiation Protection Dosimetry. 
TABLE 2. Target Detectable Intakes for Fresh $6 \%$ Plutonium Mixtures (a)

\begin{tabular}{|c|c|c|c|c|c|}
\hline Inhalation Class & $\begin{array}{c}\text { Mass of } \\
\text { Intake, } \\
\text { ng }\end{array}$ & $\begin{array}{c}238 \mathrm{Pu}, \\
\mathrm{nCi} \\
\end{array}$ & $\begin{array}{c}239+240 \mathrm{pu}, \\
\mathrm{nCi} \\
\end{array}$ & $\begin{array}{l}241 \mathrm{Pu}, \\
\mathrm{nCi} \\
\end{array}$ & $\begin{array}{r}241 \mathrm{Am}, \\
\mathrm{nCi} \\
\end{array}$ \\
\hline$Y$ & 41 & $3.5 E-1$ & 2.9 & $3.3 E+1$ & $2.1 E-3$ \\
\hline Super $Y$ & 35 & $3.0 E-1$ & 2.5 & $2.9 \mathrm{E}+1$ & $1.8 \mathrm{E}-3$ \\
\hline
\end{tabular}

(a) Assuming a particle size of 1- $\mu \mathrm{m}$ activity median aerodynamic diameter.

Although the dose equivalent that establishes the provisional TD intake is a first-year effective dose equivalent, for plutonium it is relevant to consider the 50-year committed effective dose equivalent also, especially for prospective monitoring purposes. A TD intake results in a 50-year committed effective dose equivalent of 1.2 rem for an inhalation of class $Y$ material and 2.9 rem for super class $Y$ material.

Detectability was determined for both urine sampling and chest counting for both class $Y$ and super class $Y$ plutonium.

\section{URINE SAMPLING}

Figure 1 shows the expected urinary excretion from a TD intake of class $Y$ plutonium (curve B). As shown in Figure 1, a TD intake is not detectable in urine beyond a few days after the intake. That is, urine sampling would miss a TD intake that was more than a few days old. Figure 1 also shows the expected urinary excretion that would be detectable anytime during one year following an intake. That intake would be 4.5 times the activities mentioned above for the TD intake. Therefore, the first-year effective dose equivalent from an intake of class $Y$ plutonium that would be just detectable using annual urinalysis is $450 \mathrm{mrem}$.

Figure 2 shows the expected urinary excretion from a TD intake of super class $Y$ plutonium. As shown in Figure 2, a TD intake of super class $Y$ plutonium is even less detectable than for class $Y$ plutonium. Figure 2 also shows 


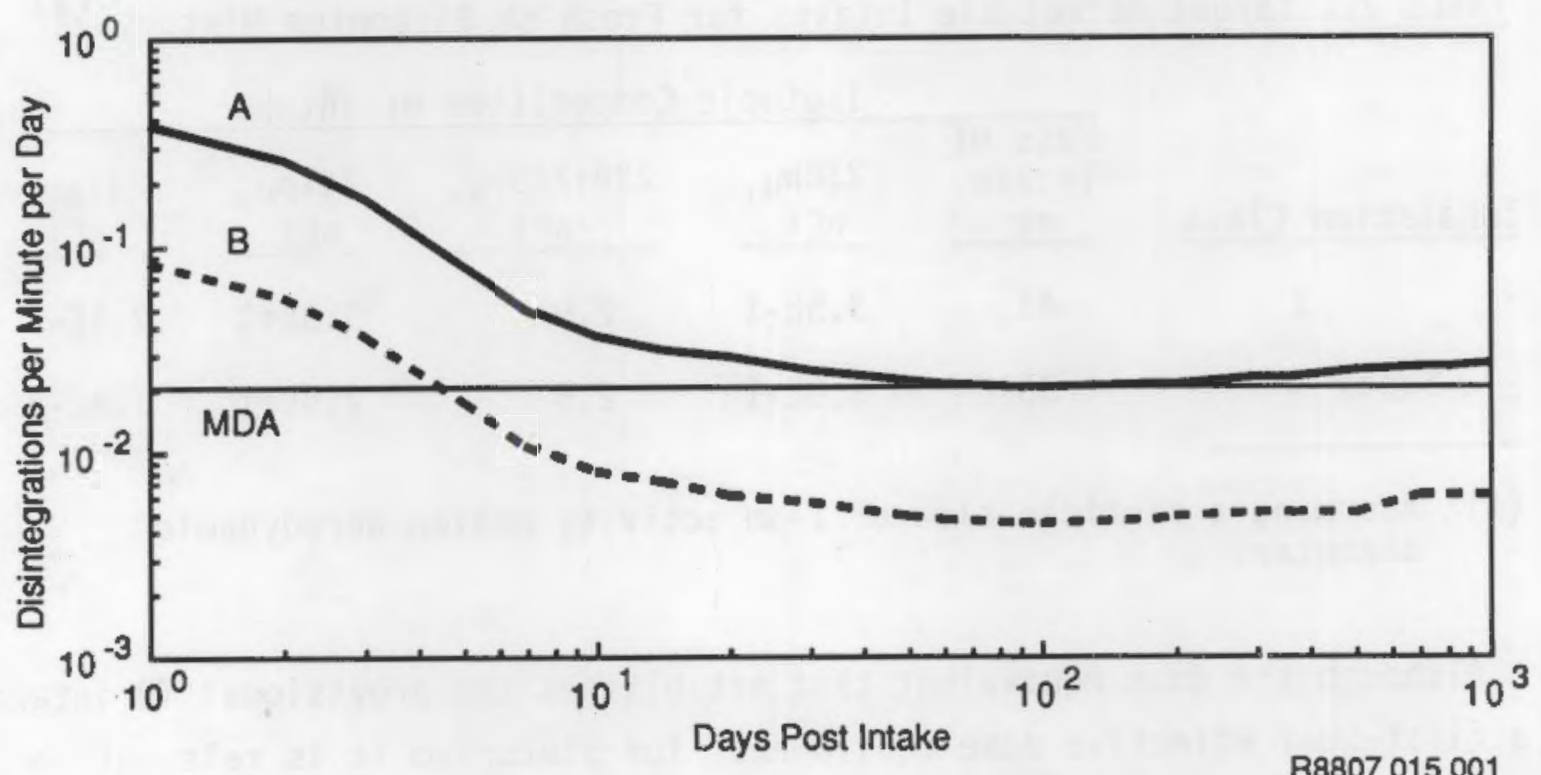

FIGURE 1. Urinary Excretion from Acute Inhalation of Class Y Plutonium A: Intake detectable by annual urine sampling

B: Target detectable intake

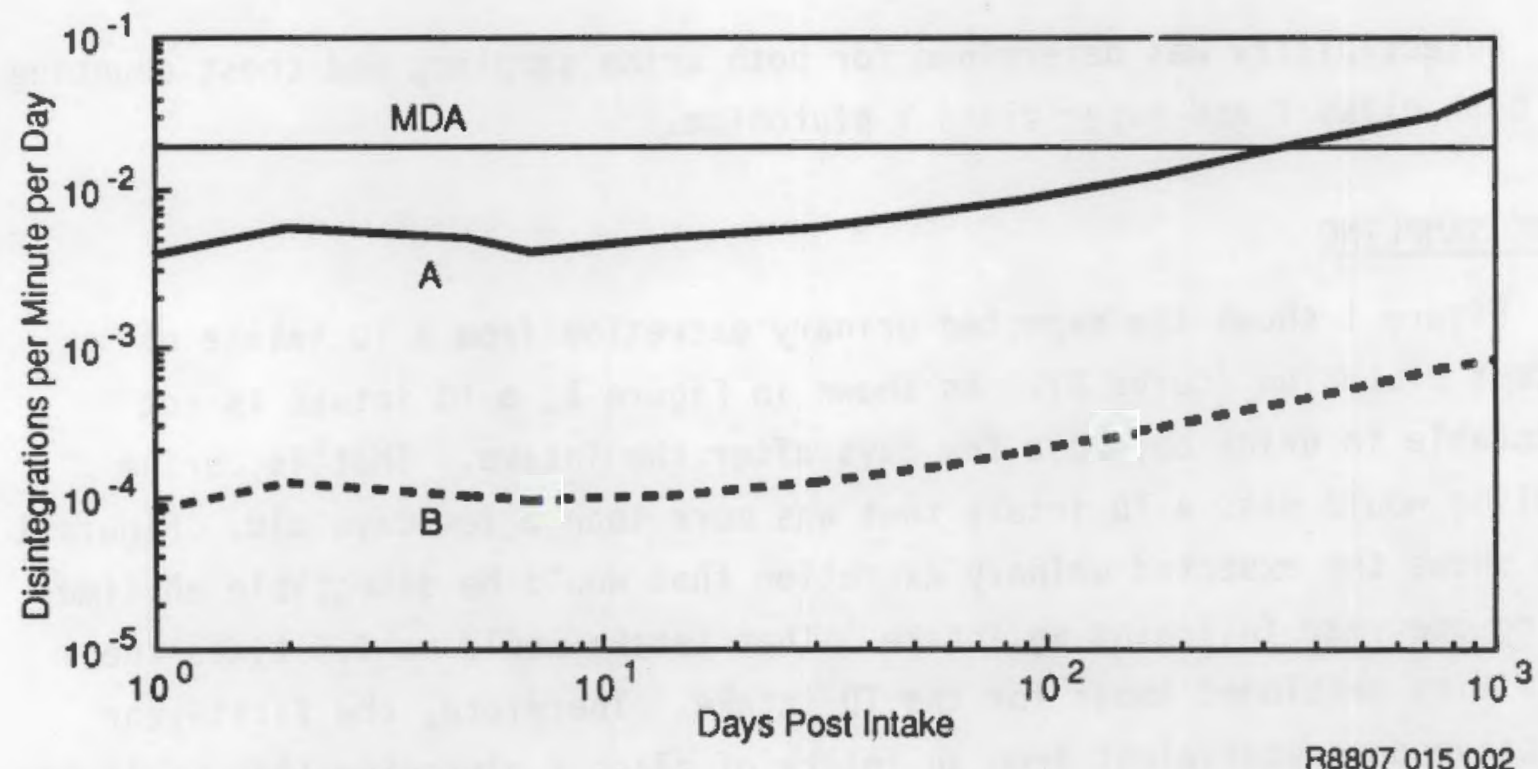

FIGURE 2. Urinary Excretion from Acute Inhalation of Super Class Y Plutonium A: Intake detectable by annual urine sampling

B: Target detectable intake 
the expected urinary excretion that would be just detectable at 365 days post intake. That intake would result in a first-year effective dose equivalent of 4700 mrem. Note that, in contrast to the excretion of class $Y$ material, the expected excretion of super class $Y$ material increases with time after the intake. Hence, an annual urine sample collected a few days after an intake would not be as effective at detecting the intake as would a sample collected hundreds of days after the intake. The range of the detectability throughout the first 365 days post intake is from $25,000 \mathrm{mrem}$ to $4700 \mathrm{mrem}$.

\section{CHEST COUNTING}

The detectability of pure 238pu or 239pu in the lung by chest counting is extremely poor. In terms of first-year effective dose equivalent at 365 days after an acute intake, the minimum detectable activities (MDAs) are about $40,000 \mathrm{mrem}$ for $238 \mathrm{Pu}$ and $100,000 \mathrm{mrem}$ for $239 \mathrm{Pu}$ for class $\mathrm{Y}$ material; and they are only a little better for super class $Y$ material. Because $241_{\mathrm{Am}}$ is much more detectable in the lung, it is commonly used as an indicator for plutonium when the activity ratio between it and plutonium is known or can be reasonably assumed.

A problem occurs, however, if the plutonium has been recently separated from americium. Americium-241 will grow back into the fresh plutonium at a rate that depends on the amount of $241 \mathrm{pu}$ present, which, in turn, depends on the burnup of the uranium that produced the plutonium. Figure 3 shows the

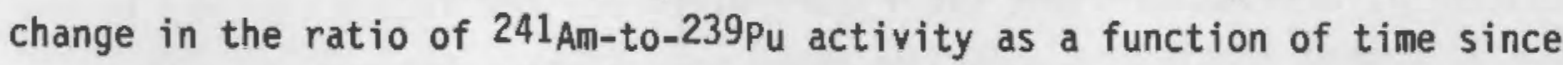
separation of the americium for two types of plutonium that generally bracket the range of burnup (expressed as weight percent of $240 \mathrm{Pu}$ ) encountered at Hanford.

It is assumed throughout this study that the $241 \mathrm{Am}-$ to- $239 \mathrm{Pu}$ ratio in the lung after the first few days post intake is the same as the ratio would 


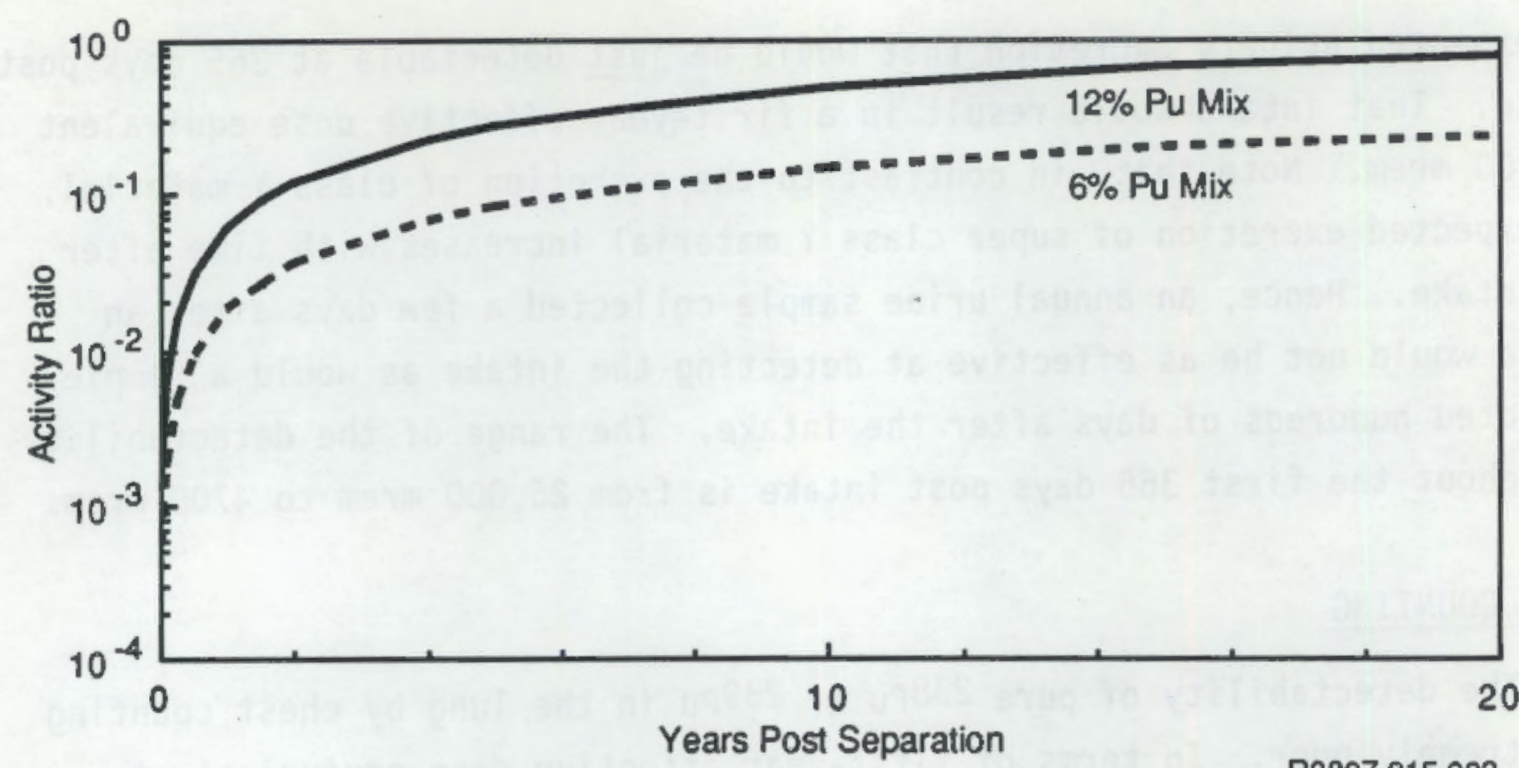

FIGURE 3. Ratio of $241 \mathrm{Am}-$ to-239Pu Activity as a Function of Time Post Separation for 6 and 12 wt\% 240 Pu Mixtures

be for the same material outside the body (Eidson 1980 and Stradling(a)). Therefore, the curves in Figure 3 apply to slowly clearing plutonium (and its ingrown americium) in the lung.

Figure 4 shows the 241 Am lung burden (including pulmonary lymph nodes) from an acute TD inhalation of class $Y$ plutonium. Such an intake would never be detected with present detection capabilities. The minimum detectable intake with a 1000-second chest count one year after the intake results in about a 4700 mrem first-year effective dose equivalent. Because the $241 \mathrm{Am}$ grows in faster than the material clears from the lung, the detectability of the intake improves with time until about 800 to 1000 days post intake (as shown by the peak in the curve in Figure 4). Thus, an intake corresponding to about a 3400 mrem first-year effective dose equivalent could be detected at about two to three years after the intake.

(a) Stradling, G. N., and J. W. Stather. "The Use of Animal Experiments for Assessing Annual Limits on Intake and Interpreting Chest Monitoring Data for Workers Exposed to Industrial Actinide Bearing Dusts." Health Physics (in print). 


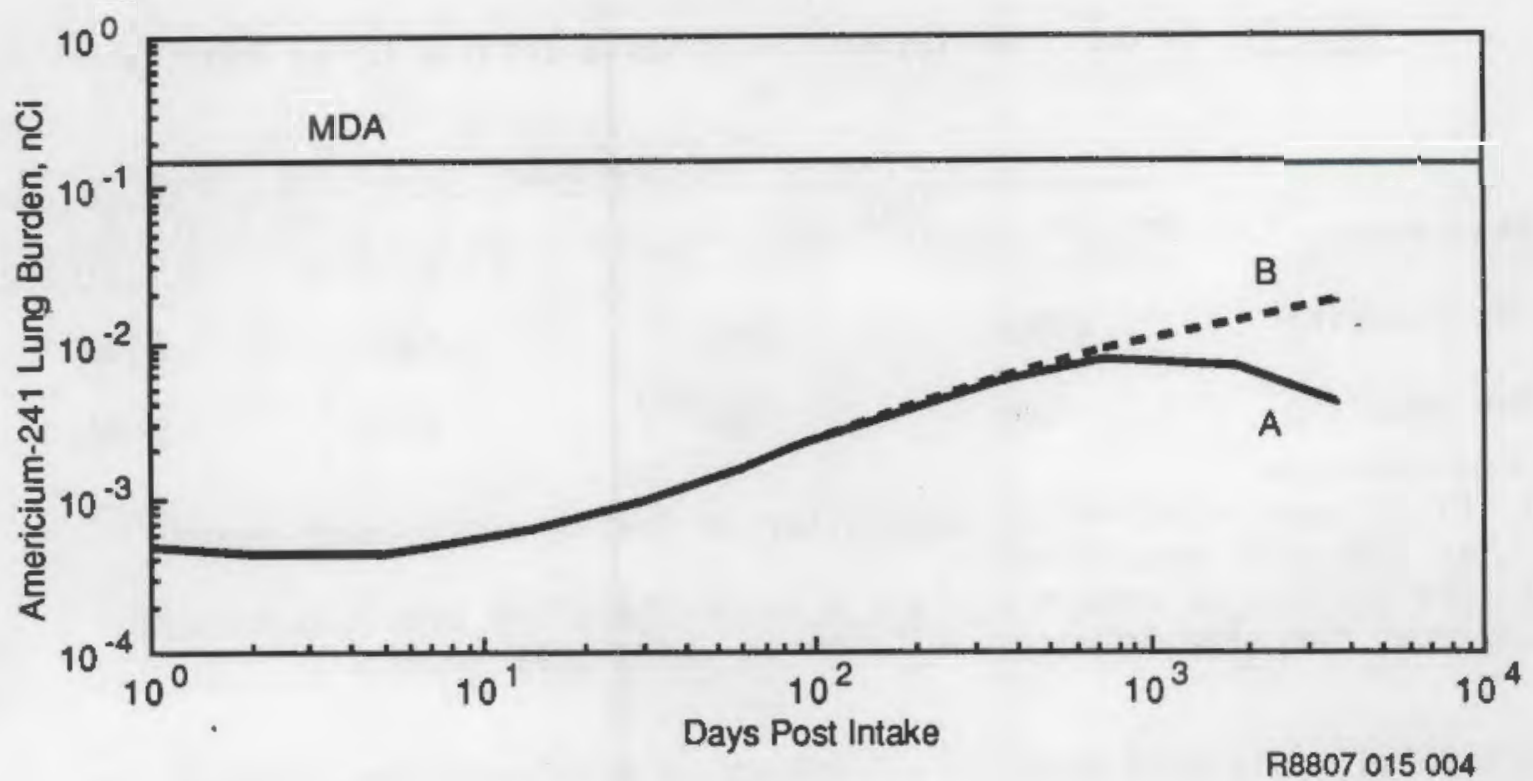

FIGURE 4. Americium-241 Lung Burden from an Acute Target Detectable Intake A: Class Y Plutonium

B: Super Class Y Plutonium

Figure 4 also shows the 241 Am lung burden from an acute TD inhalation of super class $Y$ plutonium. Such an intake would also never be detected by present routine counting. The minimum detectable intake with a 1000 -second chest count one year after the intake corresponds to about a 4400-mrem firstyear effective dose equivalent. An intake corresponding to about a $1200-m r e m$ first-year effective dose equivalent could ultimately be detected, but not until about 20 years after the intake. If the more reasonable assumption is made that a person continues to receive chest counts for three years after the intake, the minimum detectable intake would correspond to about a 2400mrem first-year effective dose equivalent.

A summary of the detectability of acute inhalations of class $Y$ and super class $Y$ plutonium using present routine bioassay-monitoring methods is presented in Table 3. Annual urine sampling is the more sensitive of the two methods for class $Y$ plutonium, and the methods have about equal sensitivity for super class $Y$ plutonium. For class $Y$ plutonium, all intakes greater than about $9 \%$ of the radiation protection standard (RPS) for workers established by the Environmental Protection Agency (1987) and proposed in draft 
TABLE 3. Doses from Minimum Detectable Intakes Using Routine Bioassay Measurements

\begin{tabular}{|c|c|c|c|c|}
\hline \multirow[b]{2}{*}{ Measurement } & \multicolumn{4}{|c|}{ First-Year Effective Dose Eq } \\
\hline & First Year(a) & Three Years & First Year & Three Years \\
\hline Chest counting & 4700 & 3400 & 4400 & 2400 \\
\hline Urine sampling & 450 & $340^{(b)}$ & 4700 & 2400 \\
\hline
\end{tabular}

(a) First year means at 365 days after an intake and 3 years means at 1095 days post intake.

(b) The ability to detect a class $Y$ intake by urine sampling remains about the same between one to three years post intake.

DOE 5480.11(a) (a 5000-mrem annual effective dose equivalent) should be detected. For super class $Y$ plutonium, all intakes greater than about $90 \%$ of the RPS should be detected at one year ( $40 \%$ at three years). Note that because of the upward slopes of the curves in Figures 2 and 4 , present routine bioassay measurements that are obtained within about 200 days of a possible super class $Y$ intake (such as termination measurements) cannot guarantee detection of an intake producing a dose at the RPS.

Figure 5 graphically summarizes the detectability of super class $Y$ plutonium at long times post intake. Doses above the curve are detectable. Figure 5 shows that within the uncertainties of the models used to generate the curves, urine sampling and chest counting have about equal sensitivity for detecting intakes regardless of time after intake. Bear in mind that the curves in Figure 5 are very dependent on the assumptions made for super class $Y$ plutonium. For instance, if the inhaled material has had more than two weeks for the $241 \mathrm{Am}$ to grow in, then detectability via chest counting will be better than that shown; similarly, if the material is more soluble than assumed, then detectability via urine sampling will also be better than shown.

(a) U.S. Department of Energy (DOE). 1987. Radiation Protection for Occupational Workers. Draft DOE 5480.11, U.S. Department of Energy, Washington, D.C. 


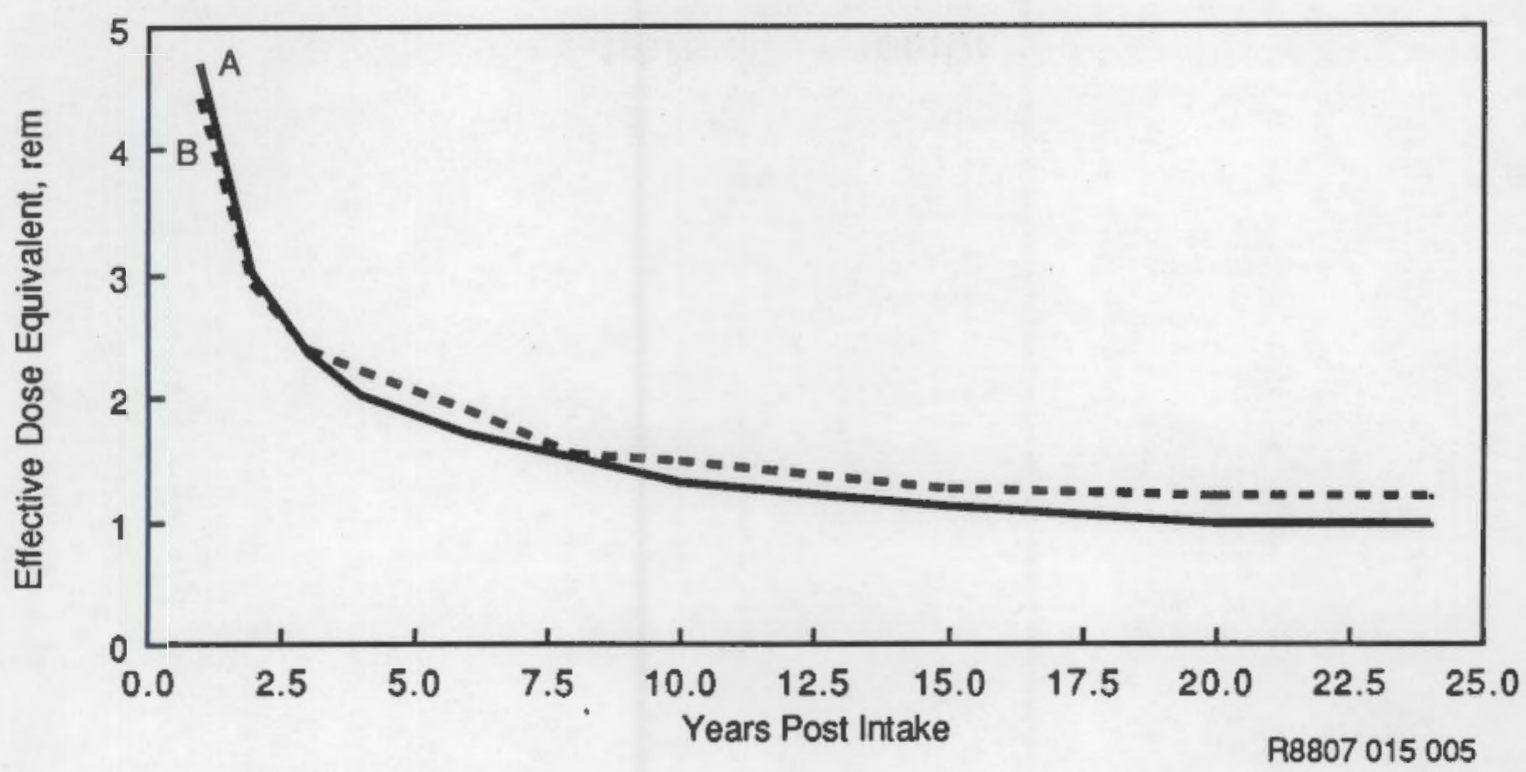

FIGURE 5. Minimum Detectable Intake of Super Class Y Plutonium in Terms of Resulting First-Year Effective Dose Equivalent

$A$ : Based on urine sampling

B: Based on chest counting 


.




\section{NEED FOR IMPROVED ROUTINE MONITORING}

The conclusions drawn from what has been presented so far are as follows:

- Lung depositions of plutonium oxide in man can be much less transportable than predicted by the ICRP 30 lung model for "classic" class $Y$ material.

- A TD intake of fresh, $6 \%$, class Y plutonium cannot be detected by the present routine bioassay-monitoring methods, and the detectability decreases with increasing retention time in the lung up to half-times in the tens of years.

The remainder of this report addresses various methods that were investigated to improve the detectability of poorly transported plutonium, of which super class $Y$ plutonium is considered the worst case. Specific methods are first discussed separately, and a preferred combination is discussed in the Conclusion and Recommendations section. 



\section{INVESTIGATION OF METHODS TO IMPROVE INTAKE MONITORING}

Each of the following four methods investigated are discussed in the following subsections:

- improved lung counting

- improved urine sampling

- routine fecal sampling

- use of DTPA to enhance urinary excretion.

\section{IMPROVED LUNG COUNTING (a)}

The easiest and quickest improvement for lung counting at Hanford is to increase the counting time to 4000 seconds (just over an hour). Four thousand seconds is about the maximum time a person can be expected to endure for a single count. With a few administrative changes, 4000-second counts can be implemented nearly immediately for at least 100 workers per year. Because the sensitivity increases approximately with the square root of the counting time the new MDA would be about $0.13 \mathrm{nCi}$ of $241 \mathrm{Am}$. A 4000 -second count should be able to detect a 1900-mrem(b) intake of super class $Y$, fresh, $6 \%$ plutonium at one year post intake and an 800 -mrem intake at three years post intake. The increase from 1000 - to 4000 -second counting times would not appreciably increase the time the worker is away from his/her work station as long as the present practice of combining routine in vivo counting and routine medical examinations on the same day continues.

Another readily available improvement is to obtain several 4000 -second chest counts and sum the spectra. Computer sumning has been shown to increase the sensitivity nearly as well as directly increasing the counting time, but breaks up the counting period into several sittings. For instance, if each worker were given a 4000 -second count every other month, the

(a) Most of the information in this section is based on personal communication with H. E. Palmer who operates the Hanford Whole Body Counter facility and who is considered an expert in the field.

(b) All doses in this section are in terms of the first-year effective dose equivalent. 
sensitivity would be the same as for an annual 24,000-second count, resulting in an MDA slightly less than $0.06 \mathrm{nCi}$ of $241 \mathrm{Am}$. This would allow detection of intakes in the 800 to 900 mrem range at one year post intake and detection of intakes of about $400 \mathrm{mrem}$ at three years post intake. This improvement could also be readily implemented for about 100 workers, especially when the additional lung counting room is operational. (The new room is scheduled for completion by early fiscal year [FY] 1989.)

The disadvantage of multiple counts in a year is the amount of time the worker spends away from his/her work location. Because of the distance between the Whole Body Counting facility and the 200 Areas, essentially half a day is lost per count. Bimonthly counts would result in about 28 production hours lost per year per person, assuming one of the counts would occur on the same day as the medical exam, compared to about 8 hours per year at present.

Another improvement would be to double the number of detectors. This is estimated to reduce the MDA by a factor of about 1.4 because the locations available to place the additional detectors would not be as optimal for detecting photons from the chest as the locations of the six detectors presently used. This option could be used in conjunction with any of the previously discussed improvements and would reduce the MDAs accordingly. This option would involve a one-time cost of about $\$ 80 \mathrm{~K}$ (1988 dollars) per lung-counter system.

The previous discussion has concerned improvements in lung counting for 241 Am. Some improvement in counting for $238 \mathrm{pu}$ and $239 \mathrm{pu}$ directly is being investigated. The effort involves lowering the background or noise in the low-energy part of the spectrum. Improvements in lowering both electronic noise and microphonic (vibrational) noise are under study, but the improvement in the MDAs from reducing these sources of noise is only about a factor of 2. This is not enough to make direct counting of plutonium routinely useful. 
Silicon detectors maintained at liquid helium temperature have better resolution (about $1 \mathrm{ev}$ for low-energy photons), which may someday impact chest counting, but they cannot be made large enough at present to be useful.

No research efforts involving potentially major breakthroughs in lowenergy lung counting are known.

Table 4 summarizes the improved MDAs presented in this section. Figure 6 , a revision to Figure 5 in the first section, incorporates the improved MDAs.

TABLE 4. Doses from Minimum Detectable Intakes Using Improved Lung-Counting Techniques

First-Year Effective Dose Equivalent, mrem

Measurement $\frac{\text { Class } Y}{\text { First Year(a) Three Years }}$ Sirst Year Three Years

Chest counting

$\begin{array}{lccrr}\begin{array}{l}\text { Annual 4000-s } \\ \text { Annual 4000-s } \\ \text { with double } \\ \text { detectors }\end{array} & 2400 & 1700 & 2200 & 1200 \\ \begin{array}{l}\text { Bimonthly 4000-s } \\ \text { Bimonthly 4000-s } \\ \text { with double } \\ \text { detectors }\end{array} & 1700 & 1200 & 1600 & 800 \\ \text { Urine sampling(b) } & 750 & 700 & 900 & 500 \\ \end{array}$

\footnotetext{
(a) First year means at 365 days after intake and three years means at 1095 days post intake.

(b) For comparison purposes only. Numbers were not changed from Table 3.
} 


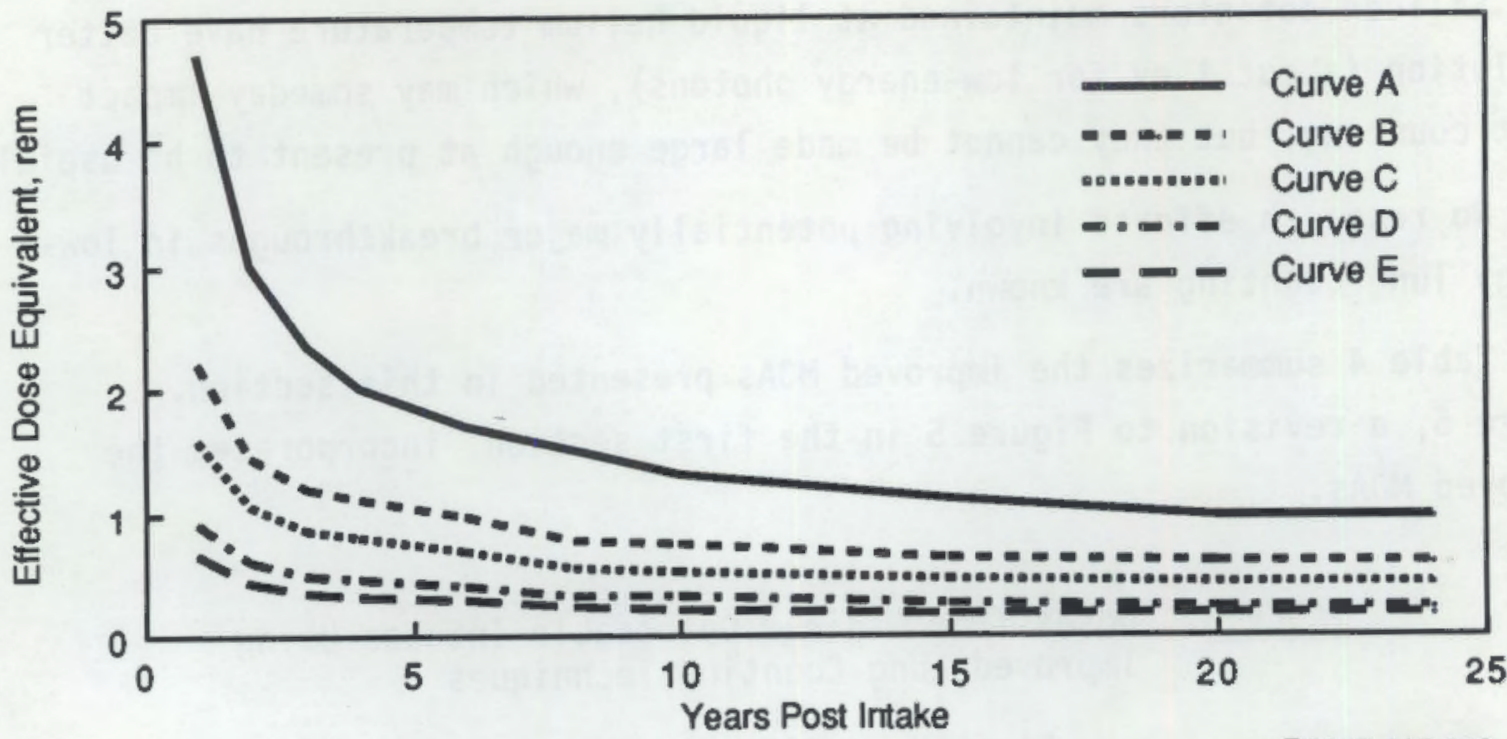

R8807015006

FIGURE 6. Revised Minimum Detectable Intakes of Super Class Y Plutonium in Terms of Resulting First-Year Effective Dose Equivalents

A: 1000-s annual chest counts

B: 4000-s annual chest counts

C: 4000-s annual chest counts with double number of detectors

D: 4000-s bimonthly chest counts

E: 4000-s bimonthly chest counts with double number of detectors

\section{IMPROVEMENTS IN URINE SAMPLING OR URINALYSIS}

Increased sampling frequency, combining two or more days' excretion into a single sample, fission track analysis, mass spectrometry, and an ionization method (under research) were considered as possible ways to enhance the monitoring of workers for poorly transported plutonium.

\section{Frequency of Sampling}

Referring back to Figures 1 and 2, it can be seen that changing the frequency of urine sampling from annual to some greater frequency would not be very helpful in enhancing the capability to detect TD intakes of poorly transported plutonium. The class $Y$ urinary excretion curve is fairly flat from about 30 days post intake on and the super class $Y$ curve increases with time. It is concluded therefore that increasing the frequency of urine sampling is not a feasible way to enhance monitoring of workers for poorly transported plutonium. 


\section{Combining Samples}

Another method to possibly lower the MDA is to combine two or more days' excretion into a single sample. Because the MDA is determined on a per-sample basis, an MDA of $0.02 \mathrm{dpm} / \mathrm{sample}$ theoretically means an MDA of $0.02 / X \mathrm{dpm} /$ day where $X$ is the number of days for which the excretion was combined.

When this possible improvement was investigated, chemists at the analytical services laboratory indicated that for sample volumes much above two liters the yield for the radiochemistry starts to drop. For sample volumes representing two or more days of urinary excretion, the loss of radiochemical yield and general unreliability of the procedure would offset gains from combining daily samples. Therefore, it was concluded that combining samples is not a feasible way to enhance monitoring of workers for poorly transported plutonium.

\section{Analytical Techniques}

A survey was conducted addressing detection limits for plutonium urinalysis routinely obtained at other DOE sites. With one exception the detection capability presently obtained by the Hanford Internal Dosimetry Program was as good as, if not better than, the other DOE sites.

The present method used by the analytical services laboratory provides an average yield from the chemistry of about $80 \%$. The $0.02 \mathrm{dpm} / \mathrm{sample}$ MDA is achieved by counting for about 40 hours. There is no practical way to improve much on either of these two factors, so the $0.02 \mathrm{dpm} / \mathrm{sample}$ MDA has to be considered a practical limit to direct radioactive counting of plutonium.

\section{An Improved Technique}

Brookhaven National Laboratory has developed a fission track analysis that results in an MDA of $0.0002 \mathrm{dpm} / \mathrm{sample}$ (Moorthy, Schopfer, and Banerjee 1988). The method has been used since 1983 and approximately 400 samples were analyzed in FY 1987. Briefly, the method consists of radiochemical separation of plutonium onto a fused silica detector, thermal neutron 
fissioning through exposure in a nuclear reactor, and fission track counting. The increased sensitivity over other, state-of-the-art, radiochemical methods results from the fissioning of the 239pu as opposed to the counting of the natural radioactivity of the $239 \mathrm{Pu}$. The latter process is constrained by the low specific activity of $239 \mathrm{Pu}$, while the fission track method depends mostly on the thermal neutron fluence of the reactor. When subjected to a thermal neutron fluence of $1017 \mathrm{n} / \mathrm{cm}^{2}$, fission track analysis is able to achieve an MDA of about $0.0002 \mathrm{dpm} / \mathrm{sample}$, a factor of 100 below the routine MDA achieved by the analytical services laboratory.

Figure 7 is a plot of the expected urinary excretion from TD intakes of class $Y$ and super class $Y$ plutonium (same curves as presented in Figures 1 and 2) contrasted to the fission track analysis MDA. The fission track analysis MDA is more than sufficient for detection of a TD intake by annual urine sampling. Technically this method looks promising.

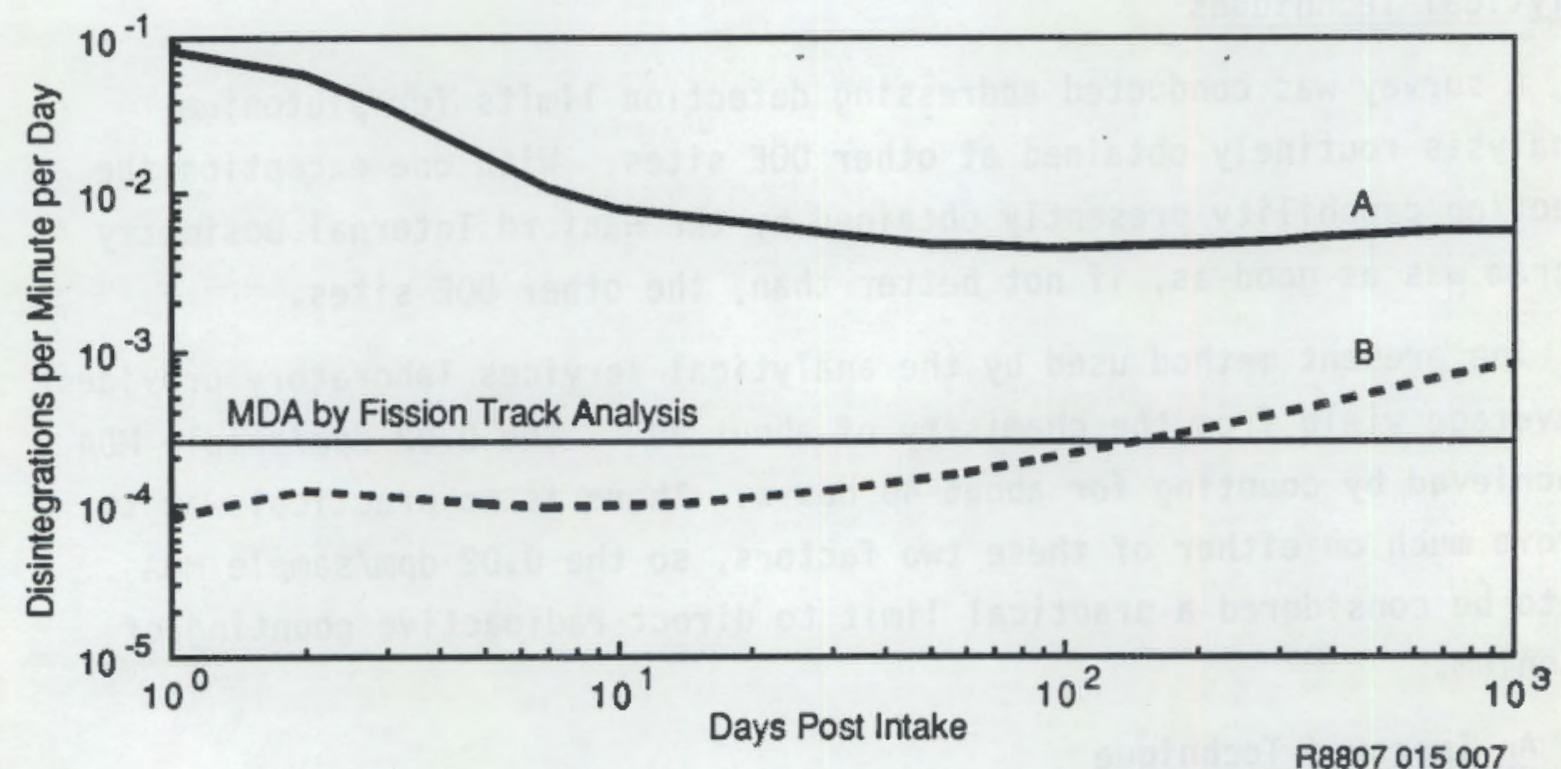

FIGURE 7. Urinary Excretion from an Acute Target Detectable Inhalation of A) Class Y Plutonium and B) Super Class Y Plutonium Compared to Brookhaven National Laboratory's MDA Adjusted for 246Pu Activity 
A quick check of the method was conducted. Two urine samples were obtained on successive days from HAN1 (see Appendix A, Table A-1). Historically, HAN1 has been excreting plutonium in urine in amounts that appear to be near the activity level that separates blank samples from positive samples, i.e., the decision level. Table 5 compares the results of the Brookhaven analyses to the recent results from samples submitted to the analytical services laboratory. Not only did Brookhaven "easily" detect the plutonium in the urine, but their results were quite comparable to Hanford's results.

\section{Possible Technical Problems}

The fission track method has some interesting difficulties that should be pointed out, however. One difficulty is that the process is subject to interference from uranium because of the high fission cross section of $235 \mathrm{U}$. A uranium decontamination factor on the order of 108 is required to achieve the stated detection level. To obtain this decontamination factor requires cleaner and more refined chemistry than presently is achieved in most laboratories including the analytical services laboratory. Brookhaven performs the plutonium-separation chemistry in a $\mathrm{Class} 100$, clean-room environment.

Another drawback to the method is that it is dependent on irradiation of the samples in a reactor to obtain the needed neutron fluence. This means that the turnaround time for sample results is subservient to the reactor's operating schedule; an extended reactor shutdown would delay reporting of results.

Finally the procedure provides results only for 239pu. Because historical reporting of results and evaluating of internal dose has been on the basis of the combined activity of $239 \mathrm{Pu}$ and $240 \mathrm{Pu}$ and because $240 \mathrm{Pu}$ adds to the internal dose, separate determination of the $240 \mathrm{pu}$ activity in urine might be necessary. For materials handled in the Hanford production facilities, however, 239pu generally accounts for about 66 to $72 \%$ of the total plutonium alpha activity and $81 \%$ of the total $239 \mathrm{Pu}$ plus $240 \mathrm{pu}$ activity. Interestingly the latter number varies only a fraction of a percent between 6 and $12 \%$ plutonium. This means that the $239 \mathrm{pu}$ results from fission track 
TABLE 5. Comparison of Plutonium in Urine As Analyzed by the Analytical Services Laboratory and Brookhaven National Laboratory(a)

\begin{tabular}{|c|c|c|}
\hline \multirow[b]{2}{*}{ Sample Date } & \multicolumn{2}{|c|}{$239+240 \mathrm{Pu}$ Activity, dpm } \\
\hline & $\begin{array}{l}\text { Analytical } \\
\text { Services }\end{array}$ & Brookhaven (b) \\
\hline $7-9-36$ & $0.014 \pm 0.0047(c)$ & \\
\hline $7-8-87$ & $0.0038 \div 0.0038$ & \\
\hline $12-3-87$ & & $\begin{array}{l}0.0099 \text { al iquot } 1 \\
0.011 \text { aliquot } 2\end{array}$ \\
\hline $12-6-87$ & & $\begin{array}{l}0.015 \text { aliquot } 1 \\
0.011 \text { aliquot } 2\end{array}$ \\
\hline
\end{tabular}

(a) Samples were collected on the dates shown from a single individual who had an acute inhalation of super class Y plutonium in 1978. Current urinary excretion is expected to be nearly constant.

(b) Results shown were adjusted for the 240 pu activity.

(c) One standard deviation of the total propagated uncertainty.

analys is could be adjusted to account for $239 \mathrm{Pu}$ plus $240 \mathrm{Pu}$ simply by dividing by 0.81 . Therefore, no separate (and very expensive) determination of $240 \mathrm{Pu}$ would be necessary.

The latter two difficulties can be overcome. The 239/240 Pu issue is easily resolved by adjusting the $239 \mathrm{Pu}$ results as just described. The lack of timely availability of a reactor is something that would just have to be accepted; there is no readily available solution. However, because the expected urinary excretion curves are very flat or slope upward from about 30 days post intake, a positive result from a routine sample could still be confirmed by additional samples even if the turnaround time for the original result was several months. And because the $241 \mathrm{Am}$ is building up in the chest during the same period, a delay in the time that a follow-up chest count would be obtained would not interfere with confirmation of the intake by chest counting. So, although a delayed sample turnaround time would slow up 
the evaluation process, it would not prevent confirmation and quantification of the intake.

Cost

The cost presently quoted by Brookhaven is $\$ 1000 /$ sample. It is anticipated that two improvements will be implemented during the next couple of years that will reduce the cost, maybe by as much as one-half. (a) on the other hand the $\$ 1000 /$ sample does not include the cost of sample collection and shipping, which might add another $\$ 100$ to the per-sample cost.

The $\$ 1100$ cost for an annual urine sample analyzed by Brookhaven is cheaper than the $\$ 1200$ cost of quarterly fecal samples plus an annual urine sample analyzed by the analytical services laboratory. However, when evaluated on an ongoing basis for, say, 100 workers including follow-up samples, the overall cost of sending urine samples to Brookhaven would probably be slightly higher, until the expected cost reductions are realized.

\section{Implementation}

If routine use of the fission track analysis were to be initiated soon, say October 1988, sample collection and shipping would probably be done by the analytical services laboratory, and sample analysis would be done by Brookhaven.

Shipping samples to Brookhaven is not a long-term solution, however. One important reason for this is that Brookhaven is a research laboratory not a production laboratory. Analys is of Hanford samples has to dovetail with whatever additional research projects Brookhaven has funding for. It is possible that additional funding for low-level plutonium analyses would not be obtained, in which case, Brookhaven might not be able to continue analys is of Hanford samples.

Ideally the Brookhaven method would be transferred to a local laboratory, preferably the analytical services laboratory. However, the cost of setting up a Class-100 environment locally--on the order of a few million

(a) Verbal communication from S. Banerjee, Brookhaven National Laboratory, March 1988. 
dollars--may be too high to be cost-effective for the analysis of only about 100 samples per year. But having Brookhaven analyze urine samples appears to be a good, short-term solution for improved urinalys is sensitivity.

\section{Mass Spectrometry}

Mass spectrometry, which like fission track analysis does not depend on radioactive decay, provides the possibility of detecting $239 \mathrm{pu}$ at a level nearly as low as the fission track analysis. Pacific Northwest Laboratory has demonstrated the capability to measure $239 \mathrm{Pu}$ in very pure water down to $0.0003 \mathrm{dpm} / \mathrm{sample}$ ( 2 femtograms/sample) for small samples. (a) The detection level for one-liter-or-larger urine samples is unknown, but ought to be of the same order of magnitude. If, for example, a detection level for urine of $0.0010 \mathrm{dpm}$ can be obtained, when adjusted for the presence of $240 \mathrm{pu}$, this represents a factor-of-20 improvement over the present detection level, and it is a factor of 5 larger than the fission track method. When compared to the excretion curves in Figure 7, mass spectrometry may be able to easily detect a TD intake at 365 days post intake for class $Y$ (curve $A$ ) or detect two to three times a TD intake for super class $Y$ (curve $B$ ).

The procedure to do low-level mass spectrometry on urine samples would need to be developed but no major obstacles are expected. The analytical services laboratory does not have the equipment to do mass spectrometry for plutonium but does have the equipment and experience at using mass spectrometry for organic compounds. So either PNL could do the analyses or the analytical services laboratory could do them if it wanted to invest the approximately three-quarter million dollars for the equipment. The ultimate cost per sample is unknown but ought to be in the same range as the cost of using fission track analysis. An advantage of mass spectrometry over fission track analysis is that, for sample activities somewhat greater than the probable detection level, activities of $241 \mathrm{Pu}, 238 \mathrm{Pu}$, and $240 \mathrm{Pu}$ would also be obtained.

(a) Verbal communication from D. M. Robertson, Pacific Northwest Laboratory, July 1988. 


\section{Research}

Another method for measuring low levels of transuranics and uranium is in early research stages (Gerke, Bushaw, and whitaker 1988). This method uses lasers to ionize atoms and a thermionic diode to detect the ions. The method is called resonantly enhanced collisional ionization. Researchers hope the method will lead to analyses of uranium and transuranics that are less costly, less time-consuming, and have somewhat lower detection levels than present radiochemical/radioactivity counting methods. If the method works, routine use of the method will be several years away.

\section{ROUTINE FECAL SAMPLING}

Several DOE sites were surveyed to examine how fecal sampling was used to monitor workers exposed to plutonium aerosols, particularly insoluble compounds. Only one of the sites contacted employs routine fecal sampling as part of its bioassay program. Fecal sampling is used primarily to confirm suspected intakes. The Idaho Chemical Processing Plant at the Idaho National Engineering Laboratory uses annual fecal sampling and annual urine sampling as the routine bioassay-monitoring program for plutonium workers. The plutonium involved is nearly pure $238 \mathrm{Pu}$ with virtually no 241 Am. At Hanford and at Los Alamos National Laboratory (LANL), fecal samples are collected soon after suspected intakes. A trial program involving quarterly collection of fecal samples has been under way at Hanford for about a year, but a good model for quantifying an intake based on fecal results beyond a few days post intake has been lacking. The merits of a routine fecal-sampling program and the feasibility of developing a fecal-excretion model were investigated as a possible means of improving the bioassay program at Hanford. A comparison of two fecal-excretion models, studies of beagle dogs, and the disadvantages of a routine fecal-sampling program are discussed in the following subsections.

\section{Comparison of Two Fecal-Excretion Models}

Two models for fecal excretion were compared--GENMOD and the Leggett/ Eckerman model. GENMOD (Johnson and Carver 1981) is a computer code based principally on the ICRP 30 lung model and ICRP $30 / 48$ retention functions but 
with considerable flexibility for changing most metabolic parameters. The Leggett/Eckerman model (Leggett 1985; Leggett and Eckerman 1987) also uses the ICRP 30 lung model, but uses more sophisticated physiological bases for movement, retention, and excretion of systemic plutonium. For the purposes of this study both models were adjusted to reflect the base-case assumptions for super class $Y$ plutonium. GENMOD was also modified to incorporate the Jones urinary excretion function (Jones 1985). GENMOD was used in two modes: one with normal systemic-to-fecal excretion and one without any systemic-tofecal excretion. The results, when normalized to a TD intake, were virtually identical for both models and both runs of GENMOD. These excretion curves are shown in Figure 8, curve A. Apparently the shape of the Leggett/Eckerman curve and the GENMOD curves are dominated by excretion directly from the lung (as opposed to excretion of systemic plutonium).

The MDA for analysis of plutonium in feces has not been firmly determined yet, but it appears to be about $0.2 \mathrm{dpm} / \mathrm{sample}$. Assuming that one sample represents total excretion for a day (a very important and probably unreliable assumption). Figure 8 indicates that within about 10 to 15 days after a TD intake the levels excreted in the feces will drop below the MDA. This implies that routine fecal sampling should optimally be done every 10 days. Not only is this not feasible, but this would mean interpreting data on the most rapidly changing portion of the curve. When sampling uncertainty is considered, this could lead to serious errors in interpretation of fecal results. If sampling is performed quarterly or semiannually, an MDA of $0.2 \mathrm{dpm} / \mathrm{sample}$ would allow for detection of about twice the TD intake if the sample represents one day's excretion.

Although both models gave the same results, they really were not independent checks on the validity of the fecal-excretion model. No empirically-based model based on actual human intakes of plutonium oxide was discovered in the literature. Dog studies have been done, and the resulting data were reviewed to see if they would confirm the appropriateness of the GENMOD and Leggett/Eckerman fecal excretion curves. The dog studies are discussed in Appendix B. 


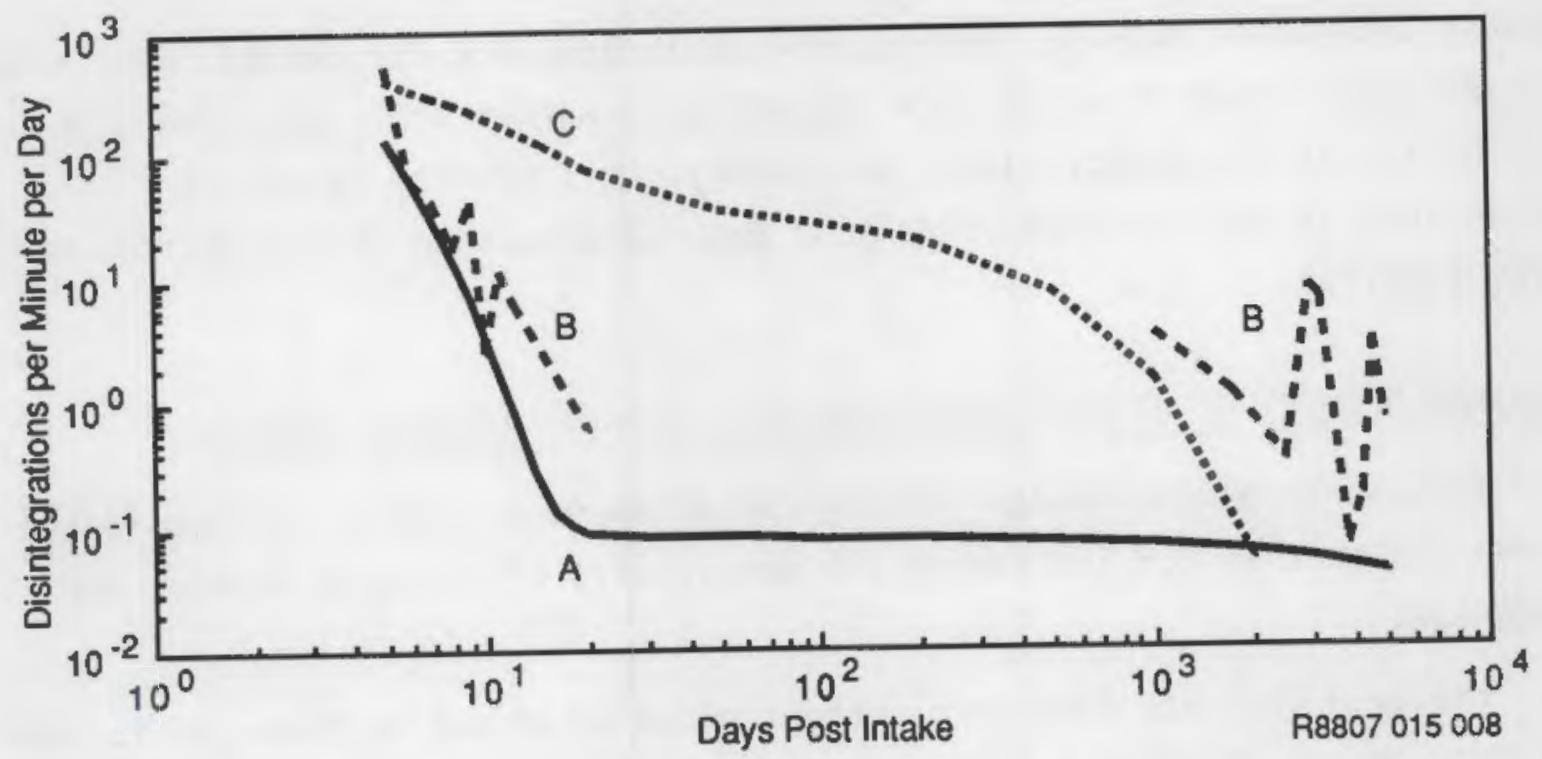

FIGURE 8. Comparison of Fecal-Excretion Models for Plutonium Oxide (Normalized to a Target Detectable Intake)

A: Leggett/Eckerman human model assuming super class $Y$ plutonium

B: Park data for a single beagle dog

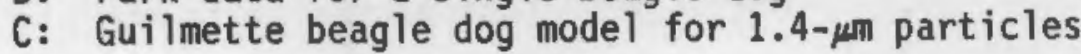

Based on this initial assessment, the beagle data that directly relate the initial pulmonary burden to the activity excreted in the feces are not readily applicable to humans. Using the beagle model will not improve the accuracy of the pulmonary-deposition estimates (as determined by fecal sampling) beyond estimates made using the ICRP-30-based models.

\section{Disadvantages}

The trial fecal-sampling program under way at Hanford has indicated that interference from intakes other than acute inhalations is a problem. This interference prompts a couple of possible responses: 1) either the "effective" detection level for detection of acute inhalations has to be raised to about $1 \mathrm{dpm} / \mathrm{sample}$ (1300-mrem first-year effective dose equivalent) or 2) better means to eliminate the interference have to be developed. The first option essentially removes the sensitivity advantage of fecal sampling relative to urine sampling (especially with fission track analysis or mass spectrometry) and the second option is costly in terms of lost work time 
because the worker must be removed from plutonium work for several days prior to sampling. Other disadvantages include poor worker acceptance and high variability in daily excretion. In summary, this program is not as meritorious as the improved urinalysis program discussed in the section on urine sampling.

\section{DRUG-ENHANCEMENT OF URINARY EXCRETION AS A ROUTINE BIOASSAY METHOD}

The use of drug-enhanced urinary excretion of plutonium was considered as one alternative for increasing the sensitivity of bioassay methods for plutonium.

The drug DTPA has long been recognized as an effective therapeutic agent for the removal of plutonium from the body (Volf 1978, NCRP 1980). The drug is approved by the U.S. Food and Drug Administration (USFDA) as an investigational new drug (IND) for the chelation of plutonium. It forms an ionic bond with plutonium, which is then readily excreted by the kidneys in urine. Human and animal data have indicated that plutonium in the blood stream and liver can be effectively removed by DTPA, whereas plutonium deposited in the bone is much less likely to be removed. During the first 24 hours following administration of DTPA, urinary excretion of plutonium may be enhanced by a factor of 50 to 100 times what might be excreted without DTPA. The typical mode of DTPA administration is by direct intravenous (IV) injection, although drip-IV injection and inhalation have also been used. The drug is considered to be safe, with no verified contraindications, particularly when used in a single-administration regime.

This enhancement effect was recognized as potentially providing an improvement in the sensitivity of urine bioassay by a factor directly proportional to the enhancement ( 50 to 100 ). To implement the use of DTPA in a routine bioassay-monitoring program would first require a modification of the USFDA IND permit. Then, special administrative procedures would be required to have the drug administered by qualified medical personnel concurrent with sample collection. Collection of a total 24-hour sample following administration would be preferred rather than a simulated 24-hour sample, because 
of the very rapid clearance of the DTPA. Experience has not indicated that DTPA interferes with the analytical process for plutonium.

Some of the logistical problems could be overcome by scheduling the bioassay to coincide with the worker's routine medical exam, which, at Hanford, is typically performed annually. The exam would then include completing the informed consent process (required by the IND status), administering the treatment, and reminding the worker of the need to provide a sample. As an alternative to the routine medical exam, the treatment could be administered at the nearest Hanford first-aid station by the assigned nurse under the direction of a physician.

For convenience, urine sample kits could be supplied to the workers by the medical staff, immediately following the treatment, thereby eliminating the need to deliver kits to the workers' homes. Once the sampling period was completed, the kit could be picked up from each worker's home like any other routine at-home urine sample. Processing the sample would be no different than that presently performed.

The potential use of this practice was discussed with the Dr. W.C. Milroy, manager of Occupational Medicine at the Hanford Environmental Health Foundation (HEHF). It was thought that with modification of the IND permit, the practice would probably not have any serious medical ramifications. However, modification of the IND permit status would likely be a lengthy process requiring months or years. In addition, the administration of an IND (or, for that matter, any drug) as a required or recommended method of bioassay monitoring would probably not be in the best ethical or legal interests of DOE or its contractors. There also could be substantial worker resistance to drug administration as part of a routine bioassay program. (It's one thing to give blood or urine samples as part of routine health or bioassay-monitoring programs; it would be quite another thing to receive a drug as part of the same program.) A potential added complication is that the IND status makes administration of the drug contingent upon approval by the subject following an informed consent process. Because a worker could not (or should not) be forced to undergo a treatment against his will, participation in a DTPA enhancement-based bioassay program would be purely 
voluntary. From the contractor perspective, a voluntary bioassay program is neither particularly attractive nor defensible.

Based on the foregoing considerations, incorporating the administration of DTPA into a routine bioassay-monitoring program for plutonium is not a recommended approach for improving bioassay-monitoring sensitivity. 


\section{CONCLUSIONS AND RECOMMENDATIONS}

This study investigated four major pathways for improved routine bioassay monitoring of workers for a possible intake of plutonium, which the authors believe cover all of the reasonable avenues available now and in the near future. All but one of these pathways are in cormon use in some form at most of the DOE facilities that handle plutonium.

\section{LUNG COUNTING}

Increasing the count time for the annual routine chest count to 4000 seconds is now a readily available option for the number of workers potentially exposed to $c$ lass $Y$ or super class $Y$ plutonium. There would be essentially no additional cost to the contractor, either in direct dollars to support the counting facility or in the time the worker would be away from the workplace. The factor of 2 increase in sensitivity is important. This change should be implemented as soon as possible.

Additional sensitivity by a factor of 1.4 would be obtainable with the expenditure of about $\$ 80 \mathrm{~K}$ to increase the number of detectors in the chest counting array from 6 to 12 . This is worthwhile because of the difficulty in determining lung dose from urinary excretion, and because it would also enhance the capability to measure uranium in the lung (which is important for a different set of workers).

If an intake of class $Y$ or super class $Y$ plutonium with little americium is confirmed by other bioassay sampling, the use of bimonthly chest counting and computer spectra summing is recomended. This is expected to be used only rarely but is a valuable aid for evaluating known intakes.

\section{URINE SAMPLING}

Probably the best and most worthwhile improvement available is in the area of urinalysis for plutonium, specifically 239 Pu. Fission track analysis of 24-hour urine samples improves the sensitivity of detection of super class $Y$ plutonium from about 47 times the TD intake to less than the TD 
intake based on annual urine sampling. The cost would be comparable to the combined cost of quarterly fecal analyses and annual urinalysis. However, long-term reliance on sending samples to Brookhaven may not be reliable. Mass spectrometry can be done locally and has a better chance of being adopted for use by the analytical services laboratory than the fission track method. The detection limit for plutonium in urine by mass spectrometry has yet to be determined but will certainly be less than the detection limit by radiochemical analysis.

Urine sampling has higher worker acceptance than fecal sampling; daily variability in urinary excretion is probably much less than for fecal excretion; there is no interference from ingestion; and the urinary excretion model is based on human data and is widely accepted.

\section{FECAL SAMPLING}

Review of literature and personal interviews with practicing plutonium dosimetrists failed to surface a fecal-excretion model based on controlled experiments. Dog data from inhalation of plutonium oxide revealed a substantially different excretion pattern than that predicted by existing human mode1s, which led the authors to conclude that an accurate fecal-excretion model for determination of intakes at long times post intake is not presently available. Fecal sampling also suffers from large person-to-person and dayto-day variability, which would complicate interpretation of data even if a valid excretion model existed. The problem of getting an ingestion-free sample is also a disadvantage. Lastly, worker acceptance is not good.

Fecal sampling, especially within the first 10 days of an intake, is a valuable tool for case evaluation; however, routine fecal sampling for discovery of an intake at long times post intake is not recomended.

\section{USE OF A DRUG TO ENHANCE URINARY EXCRETION}

The routine use of DTPA to enhance urinary excretion of systemic plutonium, thereby effectively increasing the detection capability, was found to 
be fraught with administrative, legal, and ethical problems and is not recommended.

These conclusions are summarized in Table 6 . The table also gives a ranking of the options from 1 (most preferred) to 5 (least preferred).

\section{RECOMMENDATIONS}

The following improvements are recommended for enhanced intake monitoring for workers exposed to freshiy separated, class $Y$ or super class $Y$ plutonium ( 1 isted in order of importance for implementation):

1) annual urine sampling and fission track analysis for 239pu. The combined 239pu plus 240 pu value would be determined as 1.23 times the $239 \mathrm{Pu}$ result. Brookhaven would have to perform the analyses at least for the first year. The cost would be in the range of $\$ 1100 /$ sample. Brookhaven is working on improvements to the method that they believe will reduce the cost nearly in half.

2) annual 4000-second chest counts. These could be implemented with only minor administrative changes. Time and equipment are available to count at least 100 workers per year. There would be essentially no cost to the contractor.

3) development of urinalysis by mass spectrometry. This method may prove to be almost as sensitive as fission track analysis and can be done locally. Development should take only about a year or less. Uitimate transfer of the technology to the analytical services laboratory should be easier and cheaper than for fission track analysis but would still be expensive. Pursuit of mass spectrometry capability would be a business decision made by the analytical services laboratory. Development cost is estimated at \$50K in FY 1989.

4) a 12-detector array for chest counting. Although when recomendation 1) is implemented urine sampling will be much more sensitive for quantification of an intake, large uncertainty is introduced 
TABLE 6. Summary of Findings

Method
Annual $4000-5$
chest counts
Annual urine
sampling with
fission track
andysis

Annual urine sampling with analysis by mass spec-

trometry

12-detector array for chest counting
Lead Time

Days

Months

Months

\section{Months to}

a year

Months

\section{Advantages \\ Doubles sensitivity of chest counting} for americium.

$100 \times$ improved sensitivity. Can detect TD intake.

Eliminates routine fecal sampling.

High worker acceptance. Cost projected to decrease.

10-50 x improved sensitivity. Can be done locally. Should be easier to transfer the technology than fission track analysis

$1.4 \times$ sensitivity. Gives direct lung burden compared to estimated burden from excreta sampling. Will apply to all plutonium workers. Will also improve counting for uranium. No inconvenience to

worker. No addi-

tional manpower.

Disadvantages
Slight inconvenience
for worker.
Cost including
follow-ups slightly
greater than present
program. Slow turn-
around times at
first. Technology
transfer very
expensive.
Estimated Costs
$\begin{aligned} & \text { Essentially no addi- } \\ & \text { tional. }\end{aligned}$

Rating

First year:

$\$ 1100 /$ s ample.

Longer term:

\$500-800/sample.

expensive.

Needs development

work. May not be

able to detect TD intake.

$\$ 50 \mathrm{~K}$ to prove technology and determine detection level. Additional costs to transfer technology. $\$ 1000 /$ sample analyzed by PNL. Ultimate

sample cost unknown.

\$80K 
TABLE 6. (contd)

\begin{tabular}{|c|c|c|c|c|c|}
\hline Method & Lead Time & Advantages & Disadvantages & Estimated Costs & Rating \\
\hline $\begin{array}{l}\text { Bimonthly } \\
\text { chest counts } \\
\text { with computer } \\
\text { summing }\end{array}$ & Days & $\begin{array}{l}\text { Better than double } \\
\text { the sensitivity } \\
\text { compared to annual } \\
4000-5 \text { counts. }\end{array}$ & $\begin{array}{l}\text { About } 3 \times \text { greater } \\
\text { loss of production } \\
\text { hours per year. } \\
\text { Best for confirmed } \\
\text { intake cases. }\end{array}$ & No additional. & $\begin{array}{l}4 \text { for } \\
\text { rout ine } \\
\text { use. }\end{array}$ \\
\hline $\begin{array}{l}\text { Quarterly } \\
\text { fecal sampling }\end{array}$ & None & Ongoing program. & $\begin{array}{l}\text { Data difficult to } \\
\text { interpret. Poor } \\
\text { worker acceptance. } \\
\text { Sensitivity not as } \\
\text { good as urine sam- } \\
\text { pling with fission } \\
\text { track analysis. }\end{array}$ & $\$ 1000 /$ yr/person. & 4 \\
\hline $\begin{array}{l}\text { DIPA } \\
\text { enhancement } \\
\text { of urinary } \\
\text { excretion }\end{array}$ & & highly unlikely tr & is method could get & necessary approvals. & 5 \\
\hline
\end{tabular}


when urinary excretion is used to determine lung dose. Any reasonable improvements in chest counting for 241Am should be pursued. This improvement would also enhance chest counting for uranium, which is also in dire need of improvement.

Although this report addresses only improvements in routine bioassay measurements, prompt detection of an intake followed by fecal sampling in the first five days after the intake will enhance confirmation of an intake, even for plutonium oxide. Follow-up urinalys is and chest measurements using recormendations 2) and 1) or 3) could then be used to establish the internal dose. Prompt workplace detection, then, is a very important part of the overall internal intake monitoring program. A review of intake-detection capabilities based on workplace surveying and air sampling should be performed as a companion to this document. 


\section{REFERENCES}

Environmental Protection Agency. 1987. "Radiation Protection Guidance to Federal Agencies for Occupational Exposure: Approval of Environmental Protection Agency Recommendations." Federal Register. Vol. 52, No. 17, 2822-2834.

Eidson, A. F. 1980. Comparison of Physical Chemical Properties of Powders and Respirable Aerosols of Industrial Mixed Uranium and Plutonium Oxide Fuels. NUREG/CR-1736, U.S. Nuclear Regulatory Comission, Washington, $0 . C$.

Gerke, G. K., B. A. Bushaw, and T. J. Whitaker. 1988. "Low-Level Radionuclide Analysis Using Resonantly Enhanced Collisional Ionization." Paper presented at 4th International Symposium on Resonance Ionization Spectroscopy, April 10-15, 1988, Gaithersburg, Maryland.

International Commission on Radiological Protection (ICRP), 1979. Limits for Intakes of Radionuclides by Workers. ICRP Publication 30, Pergamon Press, New York, New York.

International Comission on Radiological Protection (ICRP). 1986. The Metabolism of Plutonium and Related Elements. ICRP Publication 48, Pergamon Press, New York, New York.

Johnson, J. R., and M. B. Carver. 1981. "A General Model for Use in Internal Dosimetry." Health Physics. 41(2):341-348.

Jones, S. R. 1985. "Derivation and Validation for a Urinary Excretion Function for Plutonium Applicable Over Tens of Years Post Intake." Radiation Protection Dosimetry. 11 (1):19-27.

Leggett, R. W. 1985. "A Model of the Retention, Translocation, and Excretion of Systemic Plutonium." Health Physics. 49(6):1115-1137.

Leggett, R. W., and K. F. Eckerman. 1987. "A Method for Estimating the Systemic Burden of Plutonium from Urinalysis." Health Physics. $52(3): 337-346$.

Moorthy, A. R., C. J. Schopfer, and S. Banerjee. 1988. "Plutonium from Atomic Weapons Testing: Fission Track Analysis." Analytical Chemistry. $60(14): 857 \mathrm{~A}-860 \mathrm{~A}$.

National Council on Radiation Protection and Measurements. 1980. Management of Persons Accidently Contaminated With Radionuclides. NCRP Report No. 65, National Council on Radiation Protection and Measurements, Washington, D.C. 
Volf, V. 1978. Treatment of Incorporated Transuranium Elements. Technical Reports Series No. 184, International Atomic Energy Agency, Vienna, Austria. 
APPENDIX A

A CASE FOR SUPER CLASS Y PLUTONIUM 


\section{A CASE FOR SUPER CLASS Y PLUTONIUM}

The ICRP 30 lung model (ICRP 1979) for class $Y$ material with a 1- $\mu \mathrm{m}-$ activity median aerodynamic diameter (AMAD) particle size is shown in Figure A.1. Approximately $0.4 \%$ of the intake clears systemically in the

\begin{tabular}{|c|c|c|c|}
\hline \multirow{2}{*}{ Region } & \multirow{2}{*}{ 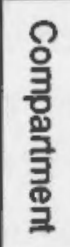 } & \multicolumn{2}{|c|}{ Y } \\
\hline & & $\begin{array}{c}T \\
\text { days }\end{array}$ & $F$ \\
\hline$\left(D_{N-P}^{N-P}=0.30\right)$ & a & $\begin{array}{l}0.01 \\
0.40\end{array}$ & $\begin{array}{l}0.01 \\
0.99\end{array}$ \\
\hline$\left(D_{T-B}^{T-B}=0.08\right)$ & $\begin{array}{l}\text { c } \\
\text { d }\end{array}$ & $\begin{array}{l}0.01 \\
0.20\end{array}$ & $\begin{array}{l}0.01 \\
0.99\end{array}$ \\
\hline $\begin{array}{c}P \\
\left(D_{P}=0.25\right)\end{array}$ & $\begin{array}{l}\text { e } \\
f \\
g \\
h\end{array}$ & $\begin{array}{r}500 \\
1.00 \\
500 \\
500\end{array}$ & $\begin{array}{l}0.05 \\
0.4 \\
0.4 \\
0.15\end{array}$ \\
\hline L & i & 1000 & $\begin{array}{l}0.9 \\
0.1\end{array}$ \\
\hline
\end{tabular}

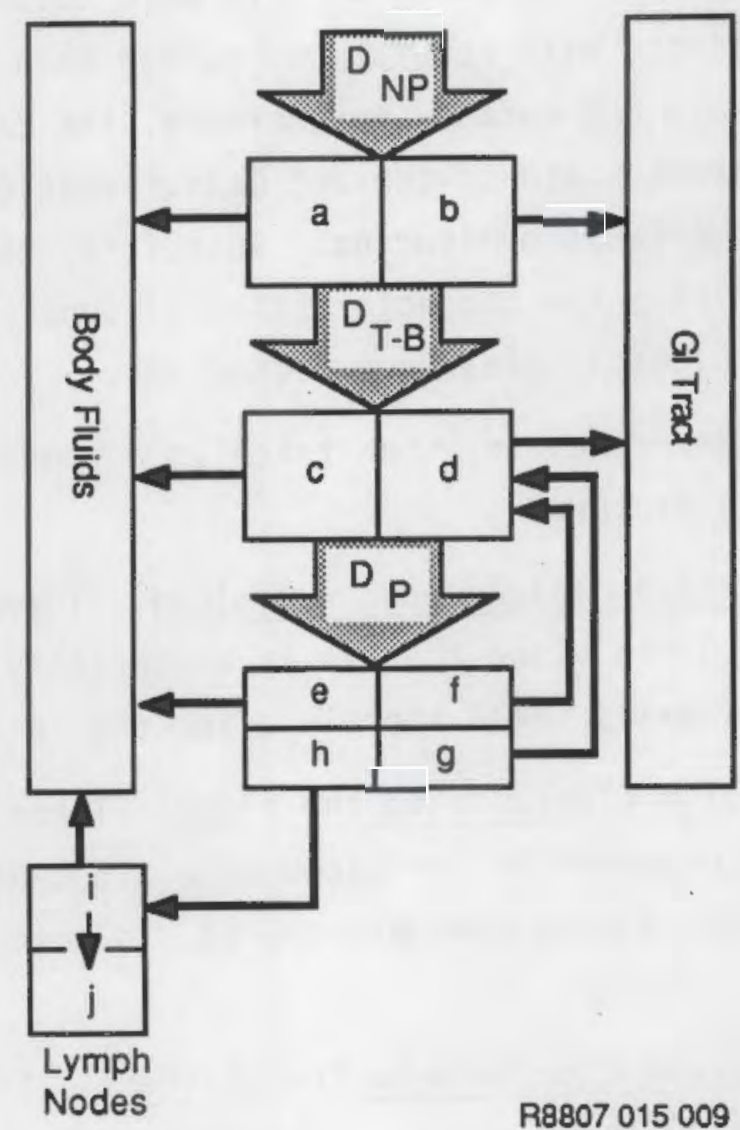

FIGURE A.1. ICRP 30 Lung Model for Class Y Material

N: nasal passage

T-B: trachea and bronchial tree

P: pulmonary parenchyma

L: lymph nodes

T: clearance half-time

$F$ : fraction of deposition, D, associated with the compartment

D: fraction of intake deposited in the region 
first day or two, and approximately half of the intake clears through the gastrointestinal (GI) tract in the first five days. The clearance in the first five days is often referred to as the early clearance. About $10 \%$ of the intake clears slowly, with a default clearance half-time of 500 days, and about $4 \%$ of the intake goes to the lymph nodes from which it clears very slowly, if at all.

A summary of human cases obtained at Hanford that appear to indicate behavior different from that predicted for class $Y$ material is given in Table A.1. The bioassay data were obtained for the purpose of determining compliance with regulations rather than for research into actual clearance pathways and rates. Furthermore, the data originate over many years covering different state-of-the-art measurement capabilities and different approaches to compliance monitoring. Therefore, the data are incomplete for fully describing the characteristics of super class $Y$ material, especially in terms of biological clearance mechanisms.

Nevertheless, when taken as a whole, the data appear to provide the following picture:

- Rapid clearance to the blood. There is so little early clearance to the blood that it is essentially undetectable even with urine samples taken shortly after the intake.

- Slow clearance to the blood. There is no detectable clearance component to the blood with a 500-day half-time. Such a clearance would have been discovered, in most of the cases, by routine urine sampling.

- Rapid clearance to the GI tract. Fecal samples were collected in only three cases. One showed early fecal clearance far below expectations from the lung model (4\% of the deposition, HAN4). One showed early fecal clearance about as expected (HAN1O). The third (HAN1) showed about half of the expected clearance, but nearly all of the clearance occurred on the first day, implying some interference from ingestion. 
TABLE A.1. Description of Human Cases

\begin{tabular}{|c|c|c|c|c|c|c|c|}
\hline $\begin{array}{c}\text { Case } \\
\text { Number }\end{array}$ & $\begin{array}{c}\text { Intake } \\
\text { Date }\end{array}$ & $\begin{array}{l}\text { Chemical } \\
\text { Form } \\
\end{array}$ & $\begin{array}{c}\text { Approximate } \\
\text { Clearance } \\
\text { Half-time, } \\
\text { days } \\
\end{array}$ & $\begin{array}{c}\text { Percent of } \\
\text { Initial } \\
\text { Pulmonary } \\
\text { Deposit (a) } \\
\end{array}$ & $\begin{array}{l}\text { Confirmed } \\
\text { by Bioassay } \\
\text { at Time } \\
\text { of Intake? } \\
\end{array}$ & $\begin{array}{c}\text { When Could } \\
\text { Have Been } \\
\text { Confirmed (b) }\end{array}$ & Facility \\
\hline HAHl & $5-23-78$ & oxide & 6,000 & $100 \%$ & yes & & $234-5 z$ \\
\hline
\end{tabular}

Discussion: Extensive contamination spread; $10,000 \mathrm{dpm}$ alpha on hand; nasal smears to $300 \mathrm{dpm}$ alpha. DTPA was given five times in first 10 days. Even so, only $0.003 \mathrm{nC} i$ total urinary excretion in first 10 days. First-day and all subsequent chest counts have been positive. Early fecal clearance was only $3 \mathrm{nCi}$ with 998 occurring on the first day post intake. Three fecal samples taken after the period of early clearance agree with very long clearance half-time. Estimated initial pulmonary deposit: $12 \mathrm{nCi}$ of $239 \mathrm{Pu}$.
HAN2
3-5-79
oxide
$>20,000$
$100 \%$
no
$1 \mathrm{yr}$
325

Discussion: General contamination spread and high airborne discovered after the fact. No nasal smears nor fecal samples. Hext-day chest count indicated nothing detectable. Intake confirmed by routine chest count two years later. Nothing in early urine nor in any urine's sample since then. Estimated initial pulmonary deposit: $3.3 \mathrm{nCi} 239 \mathrm{pu}$ plus 238pu. Potential missed dose $(c)$ : about 200 rem.

$$
\text { 3-26-64 or oxide }>10,000
$$$$
100 \%
$$

no

Discussion: Both dates involved incidents with oxide. Second date most likely for intake because of $>3000$-dpm nasal smears. Mothing was detected in urine samples after either incident. Chest counts not available in 1964. Horker left plutonium work in 1967 First chest counts, in 1987, revealed about $0.9 \mathrm{nCi}$ of $241 \mathrm{Am}$. Estimated initial lung deposit $5.4 \mathrm{nCi}$ of $239 \mathrm{pu}$. Potential missed dose: about $300 \mathrm{rem}$.

$$
\text { 8-11-70 oxide } 13,000
$$

$100 \%$

yes

0iscussion: Masal contamination about $70 \mathrm{dpm}$ alpha. Intake confirmed by chest count on day of intake. Only two of eight follow-up urine samples had detectable activity. Only $0.2 \mathrm{nci}$ of plutonium alpha in early fecal clearance. Three fecal samples taken after the period of early clearance agree with very long clearance half-time. Estimated initial pulmonary deposit: $4.6 \mathrm{nCi}$ of $239 \mathrm{Pu}$. 
TABLE A.1. (contd)

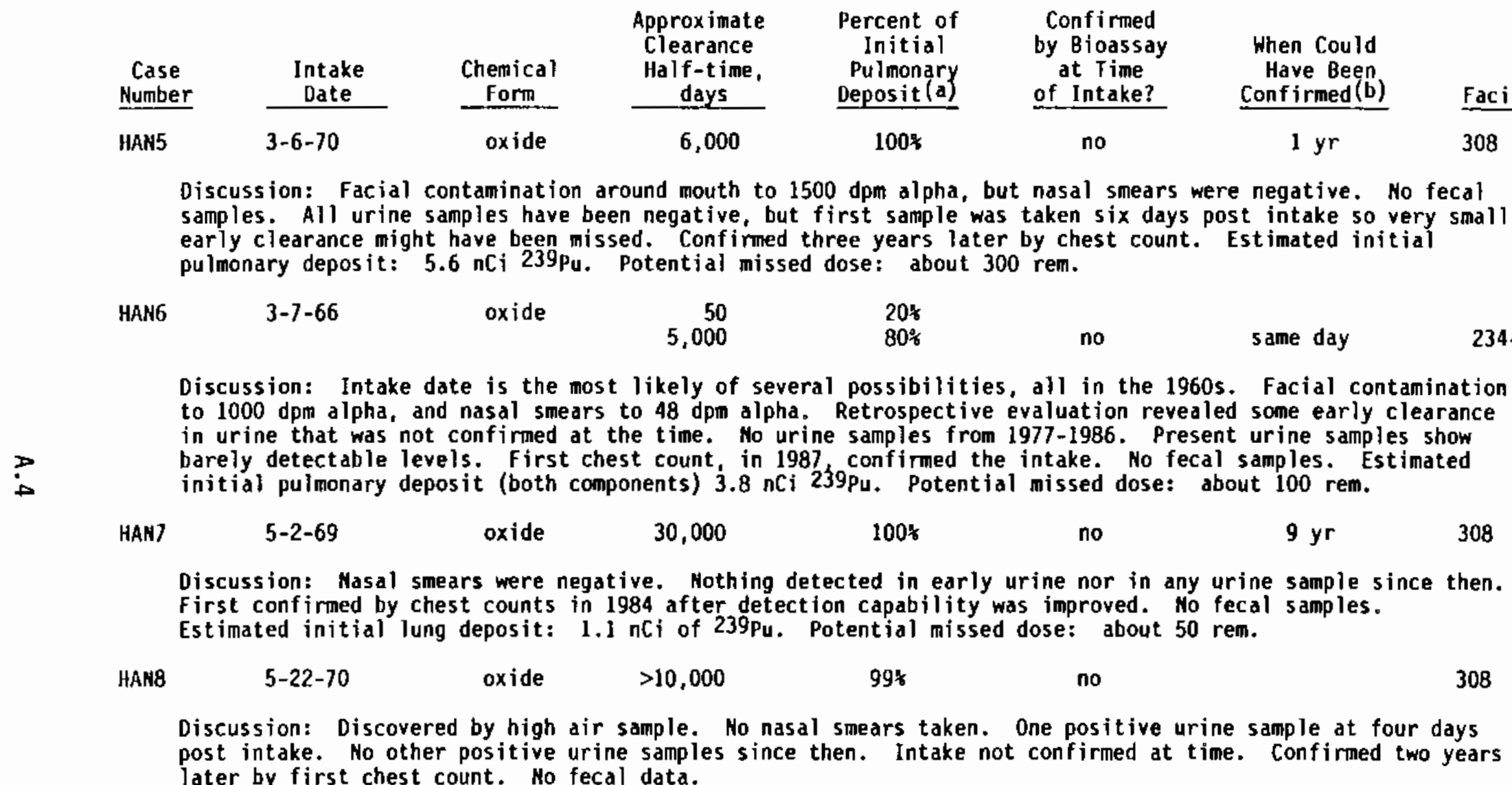

post intake. No other positive urine samples since then. Intake not confirmed at time. Confirmed two years later by first chest count. No fecal data. 
$\underline{\text { TABLE A.1. }}$ (contd)

\begin{tabular}{|c|c|c|c|c|c|c|c|}
\hline $\begin{array}{c}\text { Case } \\
\text { Number } \\
\end{array}$ & $\begin{array}{c}\text { Intake } \\
\text { Date }\end{array}$ & $\begin{array}{c}\text { Chemical } \\
\text { Form } \\
\end{array}$ & $\begin{array}{c}\text { Approximate } \\
\text { Clearance } \\
\text { Half-time, } \\
\text { days } \\
\end{array}$ & $\begin{array}{c}\text { Percent of } \\
\text { Initial } \\
\text { Pulmonary } \\
\text { Deposit (a) }\end{array}$ & $\begin{array}{c}\text { Confirmed } \\
\text { by Bioassay } \\
\text { at Time } \\
\text { of Intake? }\end{array}$ & $\begin{array}{c}\text { When Could } \\
\text { Have Been } \\
\text { Confirmed }(b) \\
\end{array}$ & Facility \\
\hline HANG & $3-5-79$ & oxide & $>20,000$ & $100 \%$ & no & $7 \mathrm{yr}$ & 325 \\
\hline
\end{tabular}

Discussion: Same incident as HAN2. No nasal smears nor fecal samples. Nothing detected in early urine, nor in any urine samples since then. Nothing detected in next-day chest count nor in annual chest counts until 1986. Estimated initial pulmonary deposit: $1 \mathrm{nCi}$ of 239pu plus 238pu. Potential missed dose: about $14 \mathrm{rem}$.
HAN10

$$
7-18-69 \text { or }
$$
oxide

$$
>10,000
$$$$
1-2 \frac{28}{98}
$$
no
$17 \mathrm{yr}$
308

Discussion: 7-18-69 incident more likely. Nasal smears measured about $100 \mathrm{dpm}$ alpha. One fecal sample at two days post intake contained $.25 \mathrm{nCi}$ plutonium alpha. Chest count on second day post intake was negative, and nine subsequent chest counts from 1973 to 1985 were also negative. First detected by 1986 chest count. All urine samples since two days post intake have been negative. Estimated initial pulmonary deposit: $0.6 \mathrm{nCi} 239 \mathrm{Pu}$. Potential missed dose: 30 ren.

In addition to the above cases, there are nine cases that have very slowly clearing material in the lung probably resulting from an intake of super class $Y$ material. But they are not listed because they involve multiple intakes or unknown intake dates and the amount of early clearance or a 500-day-type clearance is not known.

(a) In other words, was there another component clearing out of the pulmonary in addition to the one listed? In many of the cases this is a bit misleading because a component clearing to the GI tract with a half-time of days or tens of days would have been missed.

(b) Detectability based on an MDA of $0.26 \mathrm{nCi}$ of $241_{\mathrm{Am}}$ in chest counts.

(c) The 50-year committed dose to the lung that would not have been reported if the intake had not been discovered by chest counts some time after the intake. 
- Slow clearance to the GI tract. In oniy two of the cases (HANI and HAN4) were fecal samples obtained in the time period post intake that would confirm or deny the existence of a 500-day half-time clearance to the GI tract. From HAN1, one sample was collected at 280 days post intake and one at 609 days post intake. Neither sample had anywhere near enough plutonium to indicate a 500-day clearance half-time. Three samples were obtained from HAN4 at about 120 days post intake. These samples contained the amount of plutonium expected from the 13,000-day half-time obtained from chest counting, not a 500-day half-time.

In these same two cases enough $241_{\text {Am }}$ was present at intake to track the entire course of the lung deposition and clearance. In both cases the chest-count data indicated only a single component clearance rate, which was very long. So, both the limited fecal data and the chest count data rule out the presence of a component that cleared to the GI tract with a half-time in the hundreds of days.

Although there are holes in the data, the existing data point to a material that has little or no rapid clearance, especially to blood and perhaps to the GI tract, and only one other clearance component that is extremely slow, ranging from half-times of 5000 days to infinity. Whether the little clearance that may exist is to the blood, GI tract, or both is undetermined at present; however, in the one case where there is pretty good data on fecal excretion, all of the removal from the lung appears to be going to the blood not to the GI tract, at least at long times post intake.

\section{Corroborating Data}

A search of the literature did not reveal any other evidence of such extremely long retention half-times in the lung. On the other hand, dog studies of $239 \mathrm{Pu}$ oxide do indicate longer retention half-times than the 500 -day half-time of ICRP 30 (1979), especially when retention in thoracic lymph nodes is included.

Guilmette et al. (1984) gave beagle dogs pernasal inhalation exposures to monodisperse plutonium oxide particles that had been oxidized at $1150^{\circ} \mathrm{C}$. 
Three particle sizes were used $(0.72-, 1.4-$, and $2.8-\mu m$ AMAD). For dogs studied through about 800 days, lung retention (in terms of the percentage of the pulmonary burden at 4 days post intake) was described by two-component exponential decay with half-times in the tens of days and between 1000 to 2000 days, depending on particle size. The retention in the thoracic lymph nodes, however, was described by an increasing power function. When added together, the retention was essentially stable from about 500 to 800 days post intake at $64^{\circ} \%$ of the initial long-term pulmonary burden.

Park (1987) gave 130 beagle dogs inhalation exposure to poly-disperse (2.3- $\mu \mathrm{m}$ mean AMAD) $239 \mathrm{Pu}$ calcined at $750^{\circ} \mathrm{C}$. These dogs were allowed to live out their normal lifetimes, which in some cases extended to 15 years. The lung retention in terms of the percentage of the lung burden at 14 and 30 days post intake was described by a single exponential decay with a halftime of 1100 days. The thoracic lymph node retention grew rapidly for roughly the first 1000 days then approached 39\% asymptotically. The Park data indicate a combined lung/thoracic lymph node retention of about $75 \%$ at 800 days post intake, which, when the different starting points of $1-4 / 30$ days post intake (Park) and 4 days post intake (Guilmette) are accounted for, agree well with the Guilmette data.

The dog data indicate then that when thoracic lymph nodes are included the lung retention appears to become quite stable at a significant fraction of the initial long-term pulmonary burden. The difference between the dog data and the human data is that the human data do not demonstrate the exponential clearance from the lung during the first 500 days or so before the buildup in the lymph nodes affects the shape of the combined retention curve.

Human data on monodisperse fused aluminosilicate particles (FAPs), which have been used as surrogates for other very insoluble particles such as plutonium oxide, do not agree well with the dog data or with the Hanford case studies. Bailey, Fry, and James (1985) found a two-component exponential clearance in terms of the initial long-term pulmonary burden, with retention half-times of about 50 days $(20 \%)$ and about 700 days $(80 \%)$. Because these data were obtained by external counting of $85 \mathrm{Sr}$ and $88 \mathrm{Y}$ labeled FAP, the data would reflect thoracic lymph node retention as well as lung retention. 


\section{REFERENCES}

Bailey, M. R., F. A. Fry, and A. C. James. 1985. "Long-Term Retention of Particles in the Human Respiratory Tract." Journal of Aerosol Scjence. 4:295-305.

Guilmette, R. A., J. H. Diel, B. A. Muggenburg, J. A. Mtwhinney, B. B. Boecker, and R. O. McClellan. 1984. "Biokinetics on Inhaled 239PuO2 in the Beagle Dog: Effect of Aerosol Particle Size," International Journal of Radiation Biology. 45(6):563-581.

International Commission on Radiological Protection (ICRP). 1979. Limits for Intakes of Radionuclides by Workers. ICRP Publication 30, Pergamon Press, New York, New York.

Park, J. F., ed. 1987. "Inhaled Plutonium Oxide in Dogs." In Pacific Northwest Laboratory Annual Report for 1986 to the DOE Office of Energy Research. Part 1. PNL-6100 P.1, Pacific Northwest Laboratory, Richland, Washington. 
APPENDIX B

STUDIES OF FECAL EXCRETION BY BEAGLE DOGS 


\section{APPENDIX B}

\section{STUDIES OF FECAL EXCRETION BY BEAGLE DOGS}

Studies of beagle dogs exposed to plutonium oxide aerosols have also found an early clearance phase followed by long-term retention in the lung. Guilmette et al. (1984) observed short-term clearance half-times of 3.85 , 85.6, and 31.5 days in beagles exposed to $0.72-, 1.4-$, and 2.8- $\mu \mathrm{m}$ particles that had been calcined at $1150^{\circ} \mathrm{C}$. Long-term clearance in the same dogs was noted to be 693 days, 1386 days, and 1824 days for the $0.72-, 1.4-$, and 2.8- $\mu \mathrm{m}$ aerosols, respectively. Park (1987) estimated a 1100-day half-time for pulmonary clearance in beagles exposed to a plutonium-oxide aerosol fired at $750^{\circ} \mathrm{C}$ with a mean AMAD of $2.3 \mu \mathrm{m}$ and a geometric standard deviation of 1.9. These numbers represent total clearance rates from the lung not necessarily fecal-excretion rates. Guilmette defined the initial pulmonary burden as the amount of plutonium measured in the tissues of each dog at sacrifice plus the activity measured or estimated in the feces, urine, and cage wash samples from the fifth day after exposure until the day of sacrifice. Park defined the initial pulmonary burden based on external thorax counts at 14 and 30 days after exposure.

The Guilmette study also measured the actual fecal excretion from the dogs. Equations (1), (2) and (3), shown below, describe the fecal activity as a percentage of the initial pulmonary burden for the three particle sizes in the Guilmette study.

$$
\begin{aligned}
& F(.72)=2.6 \exp -0.17 t+0.18 \exp -0.21 t+0.047 \exp -0.0011 t \\
& F(1.4)=2.0 \exp -0.17 t+0.15 \exp -0.064 t+0.10 \exp -0.0033 t \\
& F(2.8)=3.7 \exp -0.23 t+0.16 \exp -0.025 t+0.050 \exp -0.0027 t
\end{aligned}
$$

Equation (2) nomalized to a TD intake is included in Figure 8 . None of the curves fit well with the GENMOD and Leggett/Eckerman curve (Johnson and Carver 1981; Leggett 1985; Leggett and Eckerman).

Fecal excrement from many of the dogs in the Park study was collected and analyzed, but the data have not been evaluated and published. An analysis of the data from two of the dogs was performed as part of this 
investigation. Both dogs were given larger intakes than would apply to worker monitoring, but one dog received a much larger intake (initial pulmonary burden about $2400 \mathrm{nCi}$ ) than the other (initial pulmonary burden about $76 \mathrm{nCl}$ ). The fecal activity from the low-dose dog (nomalized to a TD intake) is plotted in Figure 8. The pattern seems to follow the GENMOD and Leggett/Eckerman curve at early times post intake and is similar to the Guilmette curve at long times post intake. The pattern also shows the tremendous day-to-day variability associated with fecal sampling. The excretion during the first 12 days after intake was described well by both a power function $\left(y=14.5 t-2.59, R^{2}=0.86\right)$ and an exponential function $\left(y=6.89 \exp -0.55 t, R^{2}=0.84\right)$ for the low-dose dog. The data out to 5258 days did not fit either an exponential or a power function very well. The data for the high-dose dog fit a power curve ( $\left.y=15.1 \mathrm{t}-1.49, \mathrm{R}^{2}=0.92\right)$ better than an exponential curve $\left(y=0.35 \exp -0.01 t, R^{2}=0.59\right)$ out to 898 days post intake. However, because all of these equations are based on only two dogs and the functioning of the lung of the high-dose dog may have been impaired, little credence should be attributed to the equations. It would be interesting to see, when or if all of the fecal excretion data from the Park study is analyzed, if the data more closely relate to the Guilmette data or to the human models based on the ICRP 30 lung model.

\section{REFERENCES}

Guilmette, R. A., J. H. Diel, B. A. Muggenburg, J. A. Mewhinney, B. B. Boecker, and R. 0. McClellan. 1984. "Biokinetics on Inhaled 239Pu02 in the Beagle Dog: Effect of Aerosol Particle Size," International Journal of Radiation Biology. 45(6):563-581.

Johnson, J. R., and M. B. Carver. 1981. "A General Model for Use in Internal Dosimetry." Health Physics. 41(2):341-348.

Leggett, R. H. 1985. "A Model of the Retention, Translocation, and Excretion of Systemic Plutonium." Health Physics. 49(6):1115-1137.

Leggett, R. W., and K. F. Eckerman. 1987. "A Method for Estimating the Systemic Burden of Plutonium from Urinalysis." Health Physics. $52(3): 337-346$. 
Park, J. F., ed. 1987. "Inhaled Plutonium Oxide in Dogs." In Pacific Northwest Laboratory Annual Report for 1986 to the DOE Office of Energy Research. Part 1. PNL-6100 P.1, Pacific Northwest Laboratory, Richland, Washington. 


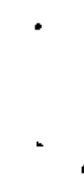




\section{DISTRIBUTION}

No. of

Copies

OFFSITE

2 DOE/Office of Scientific and Technical Information

\section{ONSITE}

5 DOE Richland Operations Office

E. A. Erichsen

D. T. Evans

J. R. Patterson

D. L. Sours

G. R. Yesberger

Hanford Environmental Health Foundation

B. D. Breitenstein

Kaiser Engineers Hanford

D. J. Foust

2 Westinghouse Hanford Company

R. 0. Budd

H. A. Decker, Jr.
No. of

Copies

41 Pacific Northwest Laboratory

W. J. Bair

S. K. Ennor

L. G. Faust

J. J. Fix (2)

D. P. Higby

G. R. Hoenes

J. R. Houston

J. R. Johnson

J. L. Kenoyer (2)

J. A. Leonowich (2)

M. Lyon (10)

J. B. Martin

J. C. McDonald

I. C. Nelson, Sr.

H. E. Palmer (2)

J. M. Selby

K. L. Soldat

M. J. Sula (2)

Publishing Coordination (2)

Technical Report Files (5)

Radiation Protection Historical Files (c/o V. L. Berndt) (2) 


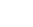

